\title{
Usability of Ultrasonic Frequency Testing for Rapid Generation of High and Very High Cycle Fatigue Data
}

\author{
Michael Fitzka ${ }^{1} \oplus$, Bernd M. Schönbauer ${ }^{1}$, Robert K. Rhein ${ }^{2}$, Niloofar Sanaei ${ }^{2}$, Shahab Zekriardehani ${ }^{2}$, \\ Srinivasan Arjun Tekalur ${ }^{2}$, Jason W. Carroll ${ }^{2}$ and Herwig Mayer $1, *$ (i) \\ 1 Department of Material Sciences and Process Engineering, Institute of Physics and Materials Science, \\ University of Natural Resources and Life Sciences (BOKU), 1190 Vienna, Austria; \\ michael.fitzka@boku.ac.at (M.F.); bernd.schoenbauer@boku.ac.at (B.M.S.) \\ 2 Center for Materials and Manufacturing, Eaton Corporation, Southfield, MI 48076, USA; \\ RobKRhein@eaton.com (R.K.R.); NiloofarSanaei@eaton.com (N.S.); ShahabZekriardehani@eaton.com (S.Z.); \\ SrinivasanArjunTekalur@Eaton.com (S.A.T.); JasonWCarroll@eaton.com (J.W.C.) \\ * Correspondence: herwig.mayer@boku.ac.at
}

check for updates

Citation: Fitzka, M.; Schönbauer, B.M.; Rhein, R.K.; Sanaei, N.; Zekriardehani, S.; Tekalur, S.A.; Carroll, J.W.; Mayer, H. Usability of Ultrasonic Frequency Testing for Rapid Generation of High and Very High Cycle Fatigue Data. Materials 2021, 14, 2245. https://doi.org/ $10.3390 /$ ma14092245

Academic Editor: Jaroslav Pokluda

Received: 31 March 2021

Accepted: 23 April 2021

Published: 27 April 2021

Publisher's Note: MDPI stays neutral with regard to jurisdictional claims in published maps and institutional affiliations.

Copyright: (c) 2021 by the authors. Licensee MDPI, Basel, Switzerland. This article is an open access article distributed under the terms and conditions of the Creative Commons Attribution (CC BY) license (https:// creativecommons.org/licenses/by/ $4.0 /)$.

\begin{abstract}
Ultrasonic fatigue testing is an increasingly used method to study the high cycle fatigue (HCF) and very high cycle fatigue (VHCF) properties of materials. Specimens are cycled at an ultrasonic frequency, which leads to a drastic reduction of testing times. This work focused on summarising the current understanding, based on literature data and original work, whether and how fatigue properties measured with ultrasonic and conventional equipment are comparable. Aluminium alloys are not strain-rate sensitive. A weaker influence of air humidity at ultrasonic frequencies may lead to prolonged lifetimes in some alloys, and tests in high humidity or distilled water can better approximate environmental conditions at low frequencies. High-strength steels are insensitive to the cycling frequency. Strain rate sensitivity of ferrite causes prolonged lifetimes in those steels that show crack initiation in the ferritic phase. Austenitic stainless steels are less prone to frequency effects. Fatigue properties of titanium alloys and nickel alloys are insensitive to testing frequency. Limited data for magnesium alloys and graphite suggest no frequency influence. Ultrasonic fatigue tests of a glass fibre-reinforced polymer delivered comparable lifetimes to servohydraulic tests, suggesting that high-frequency testing is, in principle, applicable to fibre-reinforced polymer composites. The use of equipment with closed-loop control of vibration amplitude and resonance frequency is strongly advised since this guarantees high accuracy and reproducibility of ultrasonic tests. Pulsed loading and appropriate cooling serve to avoid specimen heating.
\end{abstract}

Keywords: ultrasonic fatigue; frequency effect; strain rate effect; environmental effect; size effect; high cycle fatigue; very high cycle fatigue

\section{Introduction}

Ultrasonic fatigue testing is a powerful method to investigate the fatigue properties of materials in high cycle fatigue (HCF) and very high cycle fatigue (VHCF) regimes. Specimens are stimulated by resonance vibrations at a frequency close to $20,000 \mathrm{~Hz}$ rather than being stressed by external forces as in conventional (e.g., servo-hydraulic, rotating bending, resonance tester) fatigue tests. The high cycling frequency shortens testing times and makes fatigue investigations at extremely high numbers of cycles possible, in a regime that is hardly accessible with conventional testing due to excessive testing times. Thus, ultrasonic fatigue testing is the most appropriate technique to study fatigue properties of materials in the VHCF regime [1].

One of the main questions involved with ultrasonic testing is whether the measured fatigue data would be similarly obtained using conventional testing methods working at much lower frequencies [2-5]. Fatigue tests with servo-hydraulic test frames, resonance 
testing apparatus or rotating bending equipment are typically performed at cycling frequencies below $100 \mathrm{~Hz}$. Moreover, technical components are typically stressed at cycling frequencies far below the ultrasonic range, so that cycling frequencies in conventional tests are much more comparable to those prevailing in actual applications. It is important for high-frequency testing to consider possible frequency effects on the progress of fatigue damage and the measured fatigue lifetimes. Additionally, there are generally accepted standards for how to perform servo-hydraulic tests (i.e., measurement and control of the applied forces) or rotating bending tests (i.e., application of a defined bending moment). Although there have been individual attempts (e.g., WES 1112 [6] requiring control of displacement amplitude), a similar degree of standardisation is not available for ultrasonic tests. Different setups for ultrasonic fatigue testing are being used, which influence the accuracy and replicability of tests and the measured data.

This paper gives an overview of the existing knowledge on the applicability of ultrasonic fatigue testing for material qualification and collection of fatigue data based on the experimental data generated by the authors, as well as data gathered from the literature. An ultrasonic testing setup is described that enables reproducible and high-precision fatigue tests, avoids specimen heating, and controls, monitors and logs specimen loading. It was shown that extrinsic influences, such as size effects can influence the measured cyclic properties. The effect of a high strain rate on plastic deformation and crack initiation $[7,8]$ and the time-dependent influence of the testing environment $[9,10]$ are considered as the two, in principle, possible influences of the testing frequency on fatigue damage.

Fatigue performance of aluminium alloys, steels and titanium alloys as well as nickel alloys, magnesium alloys, fibre-reinforced polymer composites and graphite measured with conventional and ultrasonic equipment were compared based on the data available in the literature. Moreover, original fatigue data generated by the authors on a Ti6Al4V and 2024-T351 aluminium alloy by both conventional and ultrasonic fatigue were used in this study for discussion and comparison purposes. The present work aims to review and compare ultrasonic and conventional fatigue data, discuss the potential variations between these results, and offer insights into how these data correlate for each material.

\section{Materials and Methods}

\subsection{Ultrasonic Fatigue Testing Procedure}

In an ultrasonic test, an appropriately designed specimen is stimulated to resonance vibrations at close to $20 \mathrm{kHz}$. The displacement movement of the specimen is sinusoidal with time with maximum vibration amplitudes at both ends of the specimen. Cyclic loading is determined by the amplitude and frequency of the ultrasonic vibration. Strain amplitudes are highest in the centre of the specimen, where a vibration node is formed. Strain gauges are commonly used to measure the cyclic strain amplitude and to calibrate the ultrasonic fatigue test. Alternatively, several non-contact methods to measure strains at high frequencies have been employed in the past (e.g., optical interferometry based strain/displacement gauge [11], or laser vibrometry [12]). Particularly high temperatures may limit the applicability of strain gauges. They are also not suitable to be used for the actual control of the strain amplitude during a test. Cyclic stresses (or cyclic forces) cannot be measured directly but they can be calculated from the measured strains. In the high and very high cycle fatigue range, where ultrasonic fatigue testing is used, many materials show approximately linear elastic behaviour. Then, cyclic stresses, $\sigma$ are calculated from the measured strains, $\varepsilon$ with Young's modulus, $E$ and using Hooke's law (Equation (1)).

$$
\sigma=E \times \varepsilon
$$

No widely accepted standard exists for how to perform ultrasonic fatigue tests. A successfully used method to control ultrasonic loading is to measure the vibration amplitude and to control it in a closed-loop [5]. The vibration amplitude of the specimen's ends and strain amplitudes in the specimen's centre are directly proportional. Therefore, the measured vibration amplitude is a suitable signal to control cyclic loading. Vibration 
amplitude can, for example, be measured with an induction coil, with a laser vibrometer or with a gap sensor. Strain gauges attached to the specimen's centre also deliver a signal proportional to the cyclic load. However, strain gauges will fatigue and fracture during the high strains and high numbers of cycles that occur during an ultrasonic test and, therefore, are not suitable for control purposes.

By using the measured displacement signal in a closed-loop circuit, the vibration amplitude can be controlled with high accuracy. The maximum deviation between selected and actually realised vibration amplitudes can be limited to $\pm 1 \%$. In a second closedloop circuit, the stimulation frequency is controlled and kept very close to the resonance frequency of the load train within $\pm 1 \mathrm{~Hz}$. Control of stimulation frequency is necessary, since the actual resonance frequency of the system can change during the test due to slight variations of temperature or due to the initiation of a crack, for example. The vibration amplitude can be measured and the magnitude and number of cycles applied can be stored using a computer unit for backtracking the specimen's loading after fracture [5].

The measured fatigue data is strongly influenced by the chosen method of ultrasonic fatigue test. One of the most basic problems related to ultrasonic fatigue cycling is the heat generated in the specimen due to internal friction. Cyclic plastic deformation as well as the movement of interstitial atoms (i.e., Snoek effect in carbon steel) leads to heat dissipation and can increase the specimen's temperature [13,14]. If specimens are loaded continuously at ultrasonic frequencies, their temperature may increase beyond acceptable values. For about 40 years, intermittent loading with periodic sequences of pulses and cooling pauses has been known as the appropriate method to avoid specimen heating [15]. Additionally, the specimen may be cooled with forced air. Both intermittent loading and forced air-cooling are appropriate methods to limit temperature increase by a maximum of $5{ }^{\circ} \mathrm{C}$ to $10^{\circ} \mathrm{C}$ above room temperature during tests in ambient air, for example. Specimen temperature can be monitored with thermocouple or contact-free infrared thermography.

Intermittent loading requires precise closed-loop control of the vibration amplitude. Otherwise, overshoot of the amplitude at the beginning of the pulse can lead to undefined specimen loading and inaccurate tests. The rapid increase of the nominal vibration amplitude without overshoot cannot be guaranteed by all ultrasonic fatigue testing systems. Some simpler testing systems do not employ feedback control of cyclic displacement, but rather rely on controlling power output to the ultrasonic converter, which yields inferior loading amplitude accuracy. Measured ultrasonic fatigue data are influenced by the way the test is performed, the accuracy of specimen loading and the method of data evaluation. Therefore, differences between ultrasonic and conventional fatigue tests may not only be the result of intrinsic frequency influences but may also be a consequence of an improper experimental setup and an unsuitable testing procedure.

\subsection{Servo-Hydraulic Fatigue Testing Procedure}

In contrast to ultrasonic fatigue tests, testing with servo-hydraulic equipment is highly standardised regarding testing procedure, closed-loop control of static and dynamic force, data-acquisition systems and accuracy requirements. The choice of specimen geometry is not limited by the resonance criterion, also enabling investigations with specimens with large testing volumes and component testing.

Original fatigue data generated by the authors on Ti6Al4V and 2024-T351 aluminium alloys were used in this study. These tests were performed using MTS 810.10 servohydraulic fatigue testing equipment (MTS Systems Co., Eden Prairie, MN, USA) with a load capacity of $50 \mathrm{kN}$. The maximum testing frequency was $\leq 70 \mathrm{~Hz}$. Tests were performed in force-control mode with active peak-value compensation to guarantee at least $\pm 1 \%$ peak value accuracy.

\subsection{Specimen Geometry}

Specimen geometries are constrained mainly by the resonance criterion at approximately $20 \mathrm{kHz}$ for ultrasonic fatigue tests, the self-heating properties of the investigated 
material, the maximum power, and achievable displacement amplitude of the used setup. Specimen geometries can be chosen more freely in conventional fatigue tests. However, if the comparability between conventional and ultrasonic fatigue tests is investigated, it is important to have a comparable material loaded under comparable conditions.

It is necessary that the loaded volume of specimens used in both testing series is identical. If a significantly larger testing volume would be used for conventional tests, for example, lifetimes would be shifted to lower values due to the size effect. It is, therefore, sensible to use the same gauge section geometry in low-frequency and ultrasonic tests to make the results comparable.

Besides the influence of testing volume, the stress distribution in the specimens must be considered. The specimen geometry can affect the stress distribution along the specimen's length and over the load-bearing cross-section for conventional and ultrasonic resonance loading differently. Geometries featuring rectangular cross-sections, for example, exhibit a distinct stress profile across their cross-sections under resonance loading, where strain amplitudes can vary by as much as $10 \%$. It is, therefore, necessary not only to exclude a size effect, but also to guarantee comparable stress distributions over the loaded cross-sections for low and ultrasonic tests.

For the present study, authors tested fatigue performance of Ti6Al4V and 2024-T351 aluminium alloys using the same specimen geometry, as shown in Figure 1, by both servo-hydraulic and ultrasonic tests. The strain distribution along the specimen's length was calculated with AUTODESK Inventor Nastran 2021 with the Normal Modes and the Linear Static simulation types, respectively. A sufficiently high mesh resolution of $0.2 \mathrm{~mm}$ was chosen over the gauge section. Figure 1 shows that the cylindrical gauge section of $10 \mathrm{~mm}$ length experiences almost uniform strain (variation of strain amplitude is less than $1 \%$ in the modal, and $0 \%$ in the static loading case, respectively). Additionally, the stress distribution over the load-bearing cross-section (not shown) identifies less than $1 \%$ deviation from nominal stress for both loading conditions.

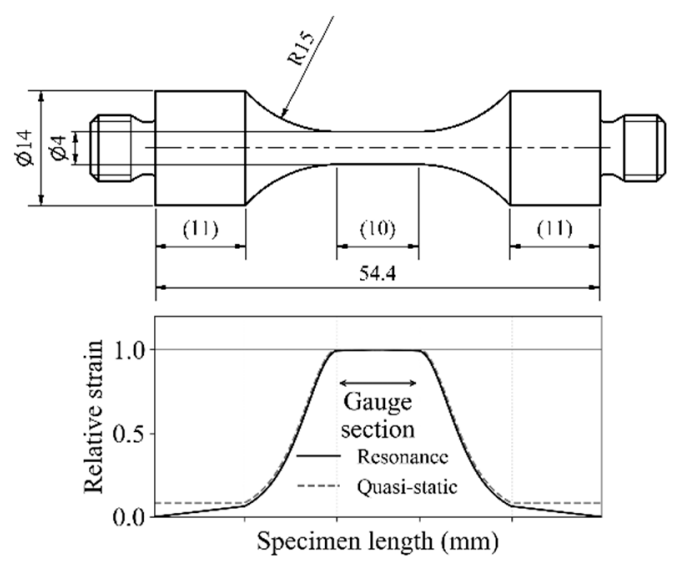

Figure 1. Specimen shape used for ultrasonic and servo-hydraulic fatigue tests (all dimensions in $\mathrm{mm}$ ); strain distribution along the specimen's length under ultrasonic resonance loading (solid line) and quasi-static (servo-hydraulic) loading (dashed line) is shown.

\subsection{Materials}

Ti6A14V and 2024-T351 aluminium alloys were tested with displacement-controlled ultrasonic fatigue testing equipment in the range $19-20 \mathrm{kHz}$ and with force-controlled servo-hydraulic or resonance fatigue tests at frequencies below $100 \mathrm{~Hz}$.

The age-hardened aluminium alloy 2024 was tested under T351 conditions (i.e., solution annealed, water quenched, cold worked and age hardened). The chemical composition of the material was (in\% mass): $\mathrm{Cu} 4.46, \mathrm{Mg} 1.42, \mathrm{Mn} \mathrm{0.61,} \mathrm{Zn} \mathrm{0.18,} \mathrm{Si} \mathrm{0.06,} \mathrm{Fe} \mathrm{0.14,} \mathrm{Cr}$ 0.005, Ti 0.025, Pb 0.0020, Ni 0.0058, Sn 0.055 and Al balance. The material was obtained in rolled plates. Mechanical properties are as follows: tensile strength $473 \pm 3 \mathrm{MPa}, 0.2 \%$ proof stress $364 \pm 4 \mathrm{MPa}$, elongation $18 \pm 1 \%$ and Vickers hardness $141 \pm 2 \mathrm{HV}$. 
Dumbbell-shaped specimens with cylindrical gauge sections were machined with their longitudinal dimension aligned to the rolling direction of the plates. The gauge sections were ground parallel to the specimen's longitudinal dimension with abrasive paper of grade 1000 to obtain well-defined surface conditions. The same specimen shape was used for fatigue testing with ultrasonic and servo-hydraulic testing equipment. Specimen shape and strain distribution along the specimen's length under servo-hydraulic and ultrasonic fatigue loading are shown in Figure 1.

The titanium alloy Ti6Al4V was tested in mill annealed condition. The chemical composition was (in\% mass): Al 6.2, V 4.1, Fe 0.06, O 0.17, N 0.004, H 0.0013, C 0.014, $\mathrm{Y}<0.001$, other impurities total $<0.04$, Ti balance. Mechanical properties of the material are as follows: tensile strength $993 \mathrm{MPa}, 0.2 \%$ proof stress $965 \mathrm{MPa}$, elongation $21 \%$ and Vickers hardness $331 \mathrm{HV}$.

Specimens were manufactured from rods with a diameter of $15 \mathrm{~mm}$. The same specimen shape was used for testing Ti6Al4V as well as for 2024-T351 (Figure 1). The surface in the gauge section is ground parallel to the specimen's longitudinal dimension with elastic grinding wheels of grade 150 (approximately equivalent to abrasive paper grade 1000). The same specimen geometry with the same surface preparation was used for servo-hydraulic and ultrasonic tests.

Fatigue tests were performed with thin sheets made of $18 \mathrm{Ni}$ maraging steel with nitrided surfaces [16]. The chemical composition was (in \% mass): Ni 18, Co 5, Mo 5, $\mathrm{Al} \mathrm{1,} \mathrm{Cr} 1$ and Fe (balance). Sheet specimens were manufactured from coil material in solution-annealed condition, followed by precipitation hardening $\left(480^{\circ} \mathrm{C}, 2.5 \mathrm{~h}\right)$ and gas nitriding. The material showed a tensile strength of $2000 \mathrm{MPa}$ and a yield strength of $1800 \mathrm{MPa}$. Vickers hardness of the nitrided surface layer was $1000 \mathrm{HV}$ and $560 \mathrm{HV}$ in the core of the sheet.

Two different specimen shapes were used in the tests, which are named large specimens and small specimens in the following [16]: The thickness of both specimens was $0.435 \mathrm{~mm}$. Large specimens had constant cross-sections in the centre with a width of $14 \mathrm{~mm}$ and a length of $20 \mathrm{~mm}$ with a $170 \mathrm{~mm}$ shoulder fillet radius. The small specimens had a width of $2.4 \mathrm{~mm}$ in the centre. The width increased towards both ends with a radius of $20 \mathrm{~mm}$. The maximum stress in small specimens was solely in the centre, whereas it was constant over a length of $20 \mathrm{~mm}$ in large specimens. Consequently, the stressed volumes were different. The material volume subjected to more than $95 \%$ of the nominal stress was $3.4 \mathrm{~mm}^{3}$ for the small specimens and $260 \mathrm{~mm}^{3}$ for the large specimens i.e., the testing volume was larger by a factor of 76 for the large specimens.

\section{Conventional and Ultrasonic Fatigue Testing}

\subsection{Aluminium Alloys}

Most aluminium alloys do not show a fatigue limit and they fail even at very high numbers of cycles [17]. However, for some cast aluminium alloys, a fatigue limit is observed. At stress amplitudes below the fatigue limit, fatigue cracks can initiate at casting porosity in these materials; however, the cracks are non-propagating and do not lead to fracture even if cycled to the VHCF regime $[18,19]$. In automotive applications, engine components, wheels and chassis components may be stressed with several hundred million cycles during service. The fatigue behaviour in the VHCF regime cannot be reliably extrapolated from HCF data, and accelerated testing techniques are therefore of great interest. Different types of aluminium-based alloys have already been investigated with ultrasonic fatigue testing, including wrought alloys, cast alloys, metal matrix composites, foams, laminates and additively manufactured (AM) alloys. Due to the low damping properties of most aluminium alloys, heat generation is low and fatigue tests can be performed with high effective frequency (i.e., test frequency considering that the specimen is not loaded continuously but in pulsed mode). Therefore, ultrasonic fatigue investigations up to $10^{9}$ cycles or beyond are possible within one or a few days. 
Fatigue lifetimes for 2024-T351 in the HCF and VHCF regimes have been the subject of several investigations in the author's laboratory, including constant and variable amplitude loading at different load ratios at low and ultrasonic frequencies [20-22] as well as ultrasonic cyclic torsion tests [23]. Fatigue performance of 2024-T351 specimens tested at $R=0.1$ and 0.5 load ratios with both displacement-controlled ultrasonic testing equipment and with force-controlled servo-hydraulic testing equipment, is shown in Figure 2. Specimens with the shape shown in Figure 1 from the same batch and with the same surface preparation were used in both testing series. Tests with servo-hydraulic equipment were performed at cycling frequencies between $8 \mathrm{~Hz}$ and $70 \mathrm{~Hz}$ and ultrasonic tests at $20 \mathrm{kHz}$. Mean lifetimes measured at $20 \mathrm{kHz}$ at $R=0.1$ were $1.7 \times 10^{5}$ cycles at $145 \mathrm{MPa}, 6.7 \times 10^{5}$ cycles at $120 \mathrm{MPa}$, and $1.1 \times 10^{7}$ cycles at $100 \mathrm{MPa}$. In servo-hydraulic tests, mean lifetimes measured at these stress amplitudes were $1.6 \times 10^{5}$ cycles, $4.8 \times 10^{5}$ cycles and $1.0 \times 10^{7}$ cycles. At load ratio 0.5 and stress amplitude $80 \mathrm{MPa}$, the mean lifetime is $1.2 \times 10^{7}$ cycles at low and $2.2 \times 10^{7}$ cycles at ultrasonic frequencies.

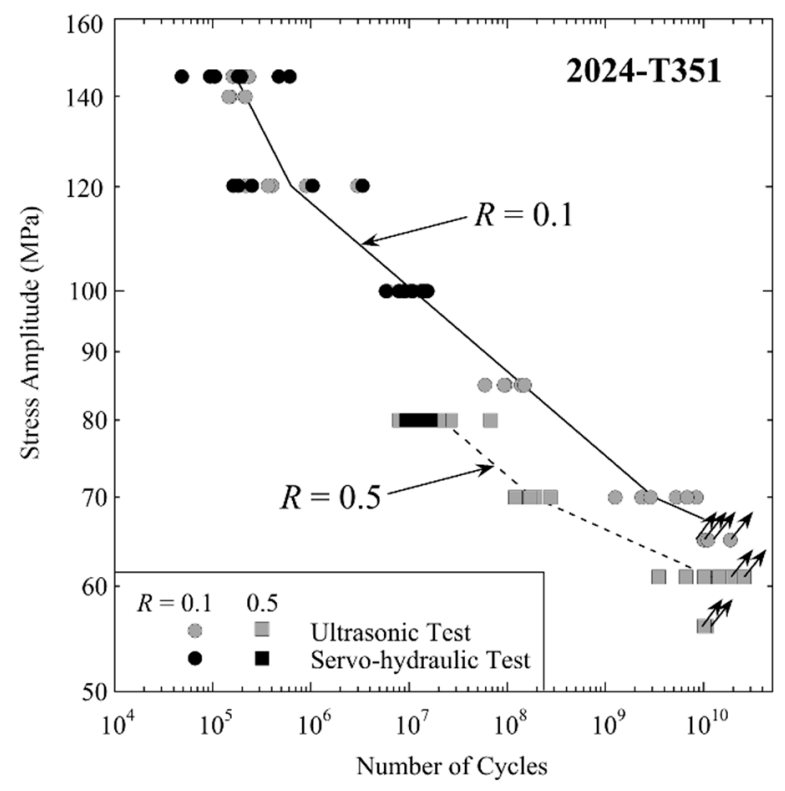

Figure 2. Fatigue data of aluminium alloy 2024-T351 measured at load ratio $R=0.1$ (circles) and $R=0.5$ (squares) with servo-hydraulic equipment at cycling frequencies between $8 \mathrm{~Hz}$ and $70 \mathrm{~Hz}$ (black symbols) and with ultrasonic equipment at $20 \mathrm{kHz}$ (grey symbols).

Considering all four testing series, the mean fatigue lifetimes were a factor 1.3 higher in ultrasonic than in servo-hydraulic tests. However, this must be compared to the scatter of fatigue lifetimes. Assuming a log-normal distribution of cycles to failure, lifetimes for $90 \%$ failure probability were factor 4 higher than those for 10\% fracture probability for ultrasonic and servo-hydraulic tests. Thus, the deviation of mean lifetimes measured in ultrasonic and servo-hydraulic tests was much smaller than the scatter of lifetimes, and no statistically significant deviation of lifetimes was found.

Fracture surfaces at the places of fatigue crack initiation after fracturing at $145 \mathrm{MPa}$ in the ultrasonic test and in the servo-hydraulic test are shown in Figure 3a,b, respectively. Cycles to failure were $9.1 \times 10^{4}$ cycles in the test at low frequency and $1.8 \times 10^{5}$ cycles in the ultrasonic frequency test. Images were obtained in backscatter electron mode to improve material contrast. Both figures show crack initiation at fractured secondary phase particles. Energy-dispersive $X$-ray analysis suggests that these are $\mathrm{Al}_{7} \mathrm{Cu}_{2}(\mathrm{Fe}, \mathrm{Mn})$ particles. Crack growth close to the particle was trans-granular, mainly quasi-cleavage fracture with a brittle appearance of the fracture surfaces. No obvious difference was found for crack initiation at low and ultrasonic frequencies indicating that the mechanism of fatigue damage is not influenced by the drastic increase of cycling frequency. 

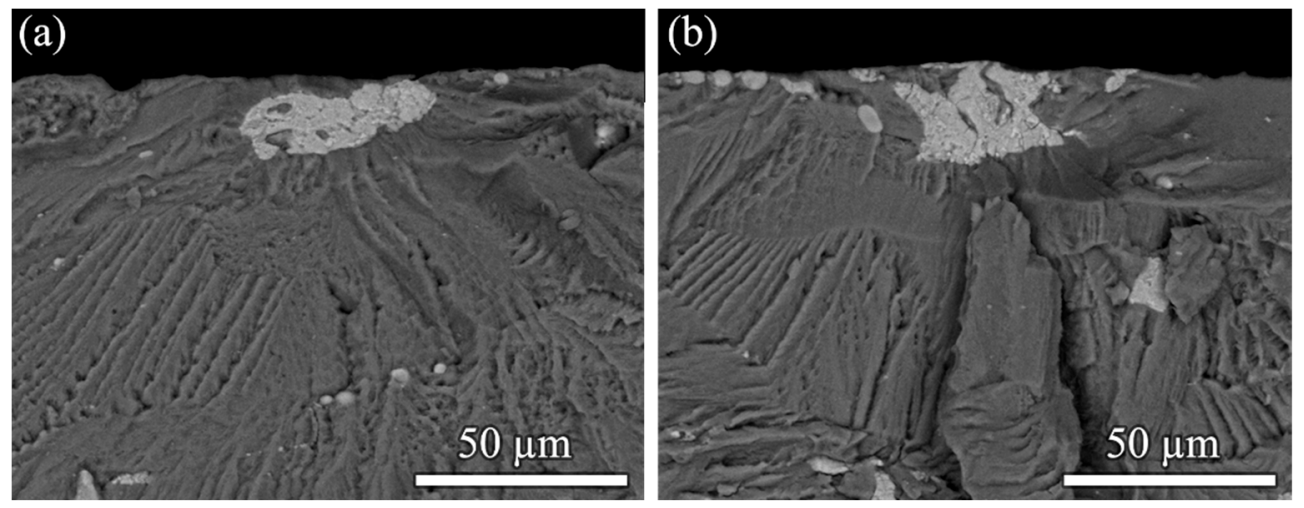

Figure 3. Fatigue crack initiation in 2024-T351 at a fractured secondary phase particle, probably $\mathrm{Al}_{7} \mathrm{Cu}_{2}(\mathrm{Fe}, \mathrm{Mn})$, cycling at stress amplitude $145 \mathrm{MPa}(\mathbf{a})$ in ultrasonic test $\left(1.8 \times 10^{5}\right.$ cycles to failure $)$ and (b) in servo-hydraulic test $\left(9.1 \times 10^{4}\right.$ cycles to failure).

A wrought aluminium alloy similar to 7075 (i.e., alloy AlZnMgCu1.5) was tested with displacement controlled ultrasonic testing equipment and with a resonant testing machine working at $100 \mathrm{~Hz}$ [24]. Fatigue data in the regime from $10^{5}$ to $10^{7}$ cycles were measured at both frequencies, and comparable lifetimes were found.

Investigation of the fatigue performance of cast aluminium alloy E319-T7 with ultrasonic and servo-hydraulic equipment by Zhu et al. [9] delivered a different result. The measurements were also performed with displacement controlled ultrasonic fatigue testing equipment, and specimens with comparable geometry and stress distribution were used in tests at $20 \mathrm{kHz}$ and $75 \mathrm{~Hz}$.

The tests were performed at $20^{\circ} \mathrm{C}, 150{ }^{\circ} \mathrm{C}$ and $250{ }^{\circ} \mathrm{C}$, and results obtained at room temperature are shown in Figure 4. The mean number of cycles to failure was increased by a factor of 5 to 10 in ultrasonic tests at all three temperatures. The extended lifetimes in ultrasonic tests are explained by the environmental influence of air humidity, which is weaker at ultrasonic than at low cycling frequency. Fatigue loading leads to early crack initiation at porosity in the cast alloy. Water vapour of ambient air diffuses to the crack tip and causes material embrittlement. At ultrasonic frequencies, the crack is not open long enough for full coverage. Thus, the chemical processes caused by water vapour act more severely in the servo-hydraulic than in the ultrasonic test, and lifetimes are prolonged. Performing ultrasonic fatigue tests in distilled water significantly decreased the lifetimes and led to an $S-N$ curve close to the $S-N$ curve at $75 \mathrm{~Hz}$ in ambient air [10].

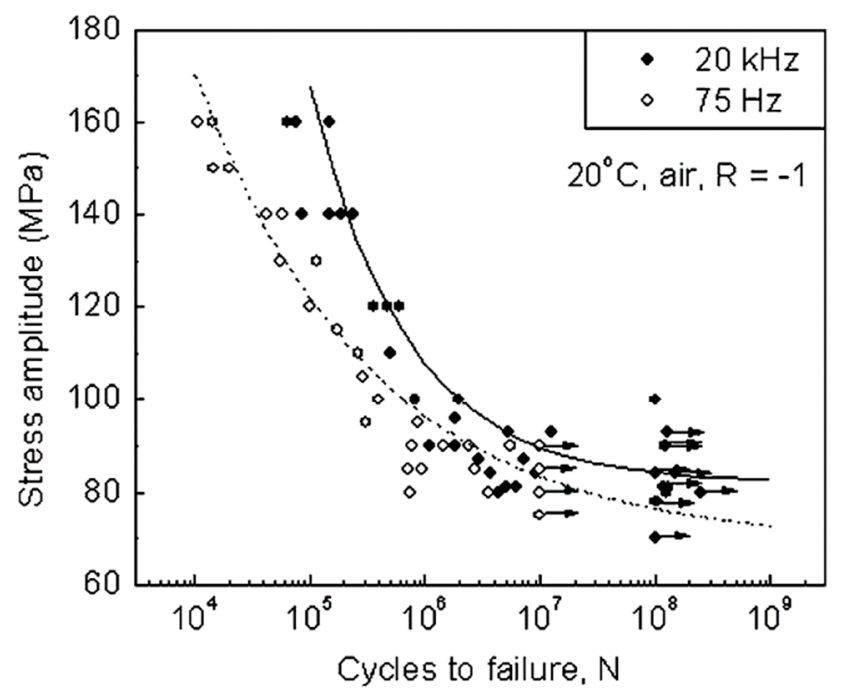

Figure 4. Fatigue data of cast aluminium E319-T7 with servo-hydraulic equipment at $75 \mathrm{~Hz}$ and with ultrasonic equipment at $20 \mathrm{kHz}$; reprinted with permission from Springer Nature [9]. 
Caton et al. [19] investigated cyclic properties of W319-T7 cast aluminium alloy using displacement controlled ultrasonic equipment and compared these results with servohydraulic tests. Microstructures with different secondary dendrite arm spacings were studied. In the range of $10^{5}$ to $10^{7}$ cycles, fatigue data were produced at $40 \mathrm{~Hz}$ and $20 \mathrm{kHz}$ cycling frequency and no frequency influence on fatigue lifetime was found. An interesting result, which could have solely been found with ultrasonic fatigue testing, was the demonstration of a fatigue limit in this cast aluminium.

The fatigue properties of $\mathrm{Al} 1 \mathrm{Mg} 0.6 \mathrm{Si}$ foam cylinders were tested at $1-10 \mathrm{~Hz}$ with a servo-hydraulic testing machine in the low and high cycle fatigue regime, and at $20 \mathrm{kHz}$ using ultrasonic equipment in the HCF and VHCF regimes [25]. Fatigue date in the overlapping regime showed no significant influence of frequency and testing procedure. The foam shows an endurance limit, where cracks initiated internally in the closed-cell structure, at holes or pre-existing cracks, but these cracks did not propagate to fracture.

The powder metallurgical aluminium-silicon alloy DISPAL ${ }^{\circledR}$ S232-T6x was tested with displacement controlled ultrasonic equipment at the authors' laboratory at $20{ }^{\circ} \mathrm{C}$ and $150^{\circ} \mathrm{C}$ [26]. In parallel, servo-hydraulic fatigue tests were performed at IWK Aachen, Germany. In the HCF regime, where fatigue lifetimes were measured with both methods, no influence of the cycling frequency was found at room or elevated temperature. Additional ultrasonic fatigue tests in distilled water delivered similar lifetimes to the ultrasonic tests in ambient air.

Additive manufactured (AM) AlSi10Mg produced by selective laser melting were studied by Awd et al. [27] with servo-hydraulic equipment at $20 \mathrm{~Hz}$ and with ultrasonic equipment at $20 \mathrm{kHz}$. They concluded that the influence of testing at ultrasonic frequencies on the measured fatigue data was not significant. Pores were found as preferential crack initiation locations at low and high cycling frequencies. Due to the possibility for rapid generation of HCF and VHCF data, the ultrasonic method is a powerful method to study AM aluminium alloys and was used to rate different alloys [28] and to investigate the influence of process parameters on cyclic strength [29].

Investigations of aluminium alloys show comparable lifetimes in ultrasonic and servo-hydraulic tests for some alloys, whereas others show prolonged lifetimes at high frequencies. Face-centred cubic ( $\mathrm{fcc}$ ) lattice structures are relatively insensitive to strain rate influences [7] which makes strain rate influences in aluminium alloys improbable. This is supported by fatigue crack growth investigations in a vacuum, where similar growth rates and threshold stress intensity factors were found at $20 \mathrm{~Hz}$ and $20 \mathrm{kHz}$ [30,31]. In ambient air, humidity causes chemical processes at the crack tip that accelerate crack growth and deteriorate the cyclic properties. The ratio of water vapour partial pressure and cycling frequency, the $p / f$ determines the diffusion rate of water vapour to the crack tip and consequently its deleterious effect. The diffusion rate is too low to allow full coverage of newly created surfaces with aluminium-hydroxide during an ultrasonic cycle $[9,10]$, whereas this is possible for ambient air conditions and conventional cycling frequencies [32,33]. Increasing the water vapour pressure in ultrasonic experiments decreases the difference measured in low and ultrasonic frequency tests. Water partial pressure can be increased by a factor of about 1000, cycling the specimen in (distilled) water instead of humid air, i.e., the $p / f$ for cycling a specimen at ultrasonic frequencies in water is in the same regime as the $p / f$ for cycling a specimen at low frequency in humid air $[9,34]$. Experiments in water can, therefore, be used to assess whether an alloy is sensitive to air humidity, and frequency effects are possible or if the alloy is insensitive and ultrasonic tests and servo-hydraulic tests deliver comparable lifetimes.

\subsection{Steels}

The failure of high-strength steels beyond the conventional fatigue limit at $10^{7}$ cycles was one of the main findings that triggered interest in the very high cycle fatigue (VHCF) regime [35-37]. Fatigue cracks preferentially initiate at the surface in the HCF regime whereas internal inclusions are a starting point for cracks leading to VHCF failure. In 
the latter case, the fracture surface in the close vicinity of the crack initiating inclusion shows a typical rough appearance, referred to as the optically dark area (ODA) [38,39] or fine granular area (FGA) [40] in tests performed at negative and slightly positive load ratios (i.e., $R=0.1$ ). An example of VHCF failure from an interior non-metallic inclusion with a distinct FGA is shown in Figure 5. Crack propagation rates inside the FGA are two or more decades below one Burgers vector per cycle and nearly exclusively determine VHCF lifetime, and failures can be found up to extremely high numbers of cycles such as $>2 \times 10^{10}$ cycles [41]. Since such high numbers of cycles can only be reached with a high-frequency testing technique, ultrasonic fatigue has become a widely used testing technique for VHCF investigations of high-strength steels.

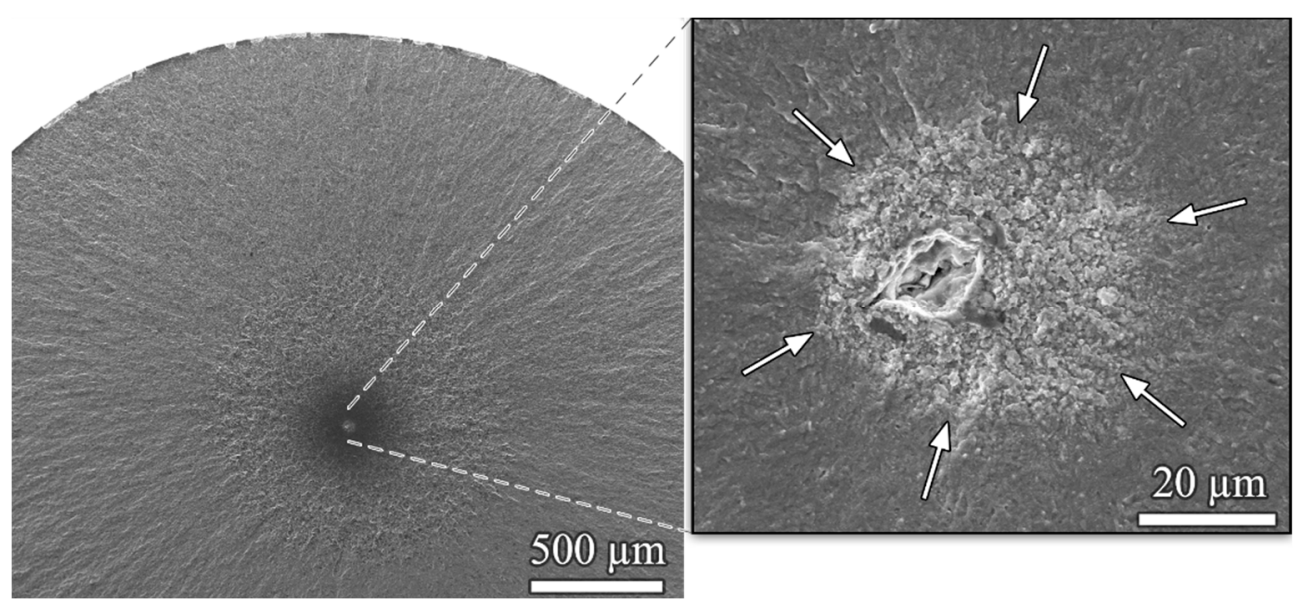

Figure 5. Fatigue crack initiation in 100Cr6 bearing steel at an interior non-metallic inclusion after ultrasonic fatigue testing at $\sigma_{\mathrm{a}}=875 \mathrm{MPa}, R=-1, N_{\mathrm{f}}=2.4 \times 10^{9}$ cycles; the border of FGA is marked with arrows.

An investigation into frequency influences on fatigue properties of high-strength steels was performed with $18 \mathrm{Ni}$ maraging steel [16]. Figure 6 shows fatigue data of maraging steel sheet specimens obtained in three testing series: large specimens (testing volume $260 \mathrm{~mm}^{3}$ ) tested at $95 \mathrm{~Hz}$, small specimens (testing volume $3.4 \mathrm{~mm}^{3}$ ) tested at $95 \mathrm{~Hz}$, and small specimens tested at $20 \mathrm{kHz}$.

The result of the investigation shows that there is a strong size effect in this maraging steel. Mean lifetimes measured with large specimens are about one order of magnitude lower than mean lifetimes of small specimens. This is found when cycling the small specimen at ultrasonic frequencies (Figure 6a) or cycling both specimens at the same low frequencies (Figure $6 \mathrm{~b}$ ). In contrast, when cycling small specimens at low and ultrasonic frequencies, the difference in mean lifetimes is within the range of scatter (Figure 6c). The mean size of inclusions in large specimens is $9.9 \mu \mathrm{m}$, whereas it is $4.4 \mu \mathrm{m}$ in small specimens. For the fatigue crack initiating at an internal inclusion, this means that the starting crack length was longer in large specimens, which shortened the crack propagation period and decreased the fatigue lifetime.

Cracks initiated exclusively at aluminates in large specimens. Crack initiation was at aluminate and $\mathrm{Zr}(\mathrm{N}, \mathrm{C})$-inclusions in small specimens for cycling with both $95 \mathrm{~Hz}$ and $20 \mathrm{kHz}$. Fracture of the interface between aluminates and matrix and particle fracture of the (smaller) $\operatorname{Zr}(\mathrm{N}, \mathrm{C})$-inclusions are the two crack initiating mechanisms. Due to the small highly stressed volume in small specimens, about half of the samples do not contain aluminate inclusions large enough to initiate a crack, and failure is caused by the smaller $\mathrm{Zr}(\mathrm{N}, \mathrm{C})$ inclusions.

Japanese Researchers from the National Institute of Materials Science performed ultrasonic fatigue and multiple-axis, cantilever-type, rotating bending fatigue testing [42], up to $10^{10}$ cycles which took more than 3 years at $100 \mathrm{~Hz}$. No frequency effects were found for the two investigated high-strength steels (spring steel SUP7 and low-alloy steel 
SCM440) as shown in Figure 7. The same research group further demonstrated that the size of the specimens significantly affects the fatigue lifetimes even in the VHCF regime [43,44] due to a lower probability of large inclusions in small testing volumes-as discussed for $18 \mathrm{Ni}$ maraging steel sheets.
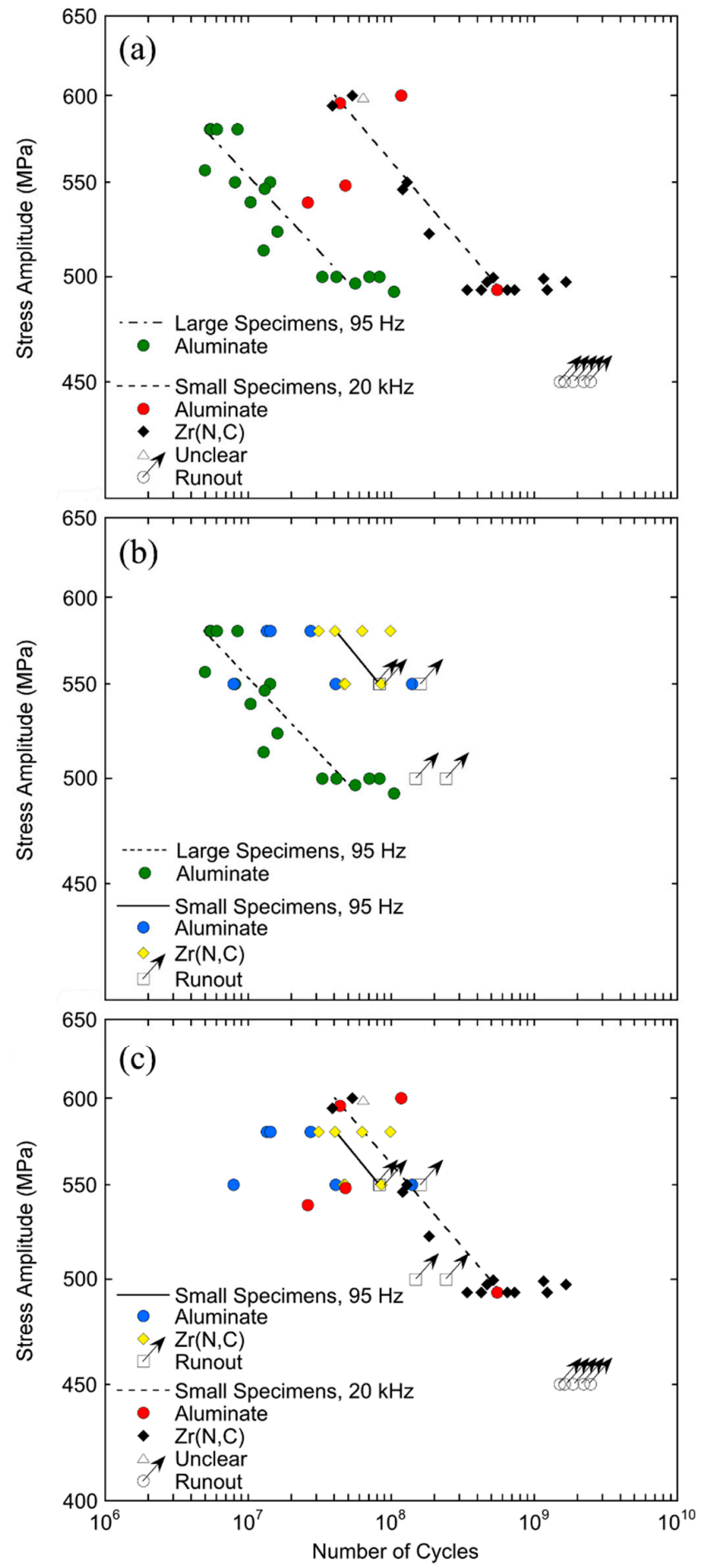

Figure 6. Comparison of $S-N$ data at load ratio $R=0.1$ (a) of large specimens tested at $95 \mathrm{~Hz}$ and of small specimens tested at $20 \mathrm{kHz}$; (b) of large and small specimens tested at $95 \mathrm{~Hz}$; (c) of small specimens tested at $95 \mathrm{~Hz}$ and $20 \mathrm{kHz}$; crack initiation was at internal aluminate inclusions (circles) or at internal $\mathrm{Zr}(\mathrm{N}, \mathrm{C})$ inclusions (diamonds); runouts are marked with arrows; reprinted with permission from Elsevier [16]. 

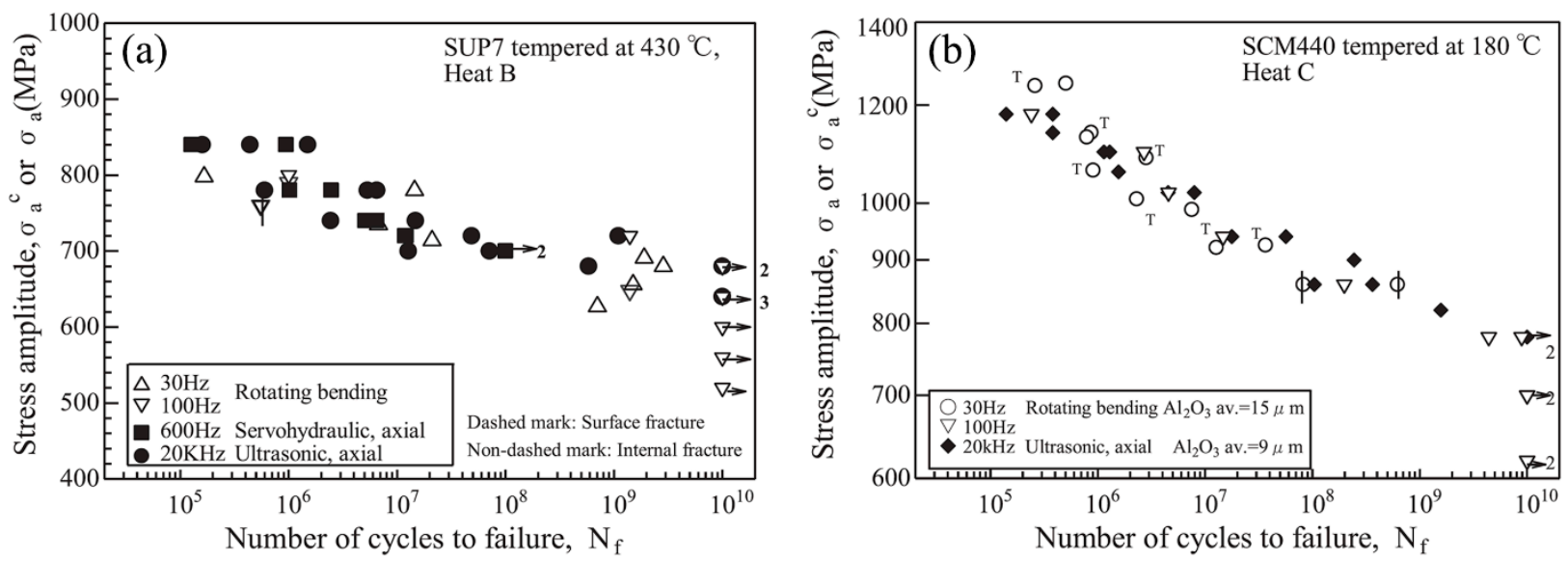

Figure 7. Fatigue data of high-strength spring steel SUP7 (a) and low-alloy steel SCM440 (b) with rotating-bending equipment $(30 \mathrm{~Hz}$ and $100 \mathrm{~Hz})$, servo-hydraulic equipment $(600 \mathrm{~Hz})$, and ultrasonic equipment at $20 \mathrm{kHz}$ [42].

In addition to the examples demonstrated above, several investigations of the VHCF properties of martensitic stainless steels [41,45-47] have shown that ultrasonic frequencies do not affect the fatigue lifetimes if the failure occurs due to inherent defects such as non-metallic inclusions.

In contrast to martensitic steels, where the inclusion size is large compared to the characteristic microstructural size (block size) [48], austenitic steels may rather fail due to crack initiation at surface slip bands. In this case, it can be assumed that the austenite grain size determines the fatigue strength. Bending fatigue tests at $160 \mathrm{~Hz}$ to $200 \mathrm{~Hz}$ and ultrasonic fatigue tests at $20 \mathrm{kHz}$ were performed with tubular specimens made of austenitic stainless steel AISI904L by Carstensen et al. [49] (Figure 8), where no frequency effect was observed. Ultrasonic and resonance pulsating fatigue tests at $150 \mathrm{~Hz}$ were also performed with austenitic stainless steel AISI316L steel [50]. A significantly increased fatigue limit and prolonged fatigue lifetimes were observed at $20 \mathrm{kHz}$. The strong damping property of austenitic steel required to use specimens with much smaller testing volume in ultrasonic tests, and the difference in measured strength was attributed to frequency as well as scale effects [50].

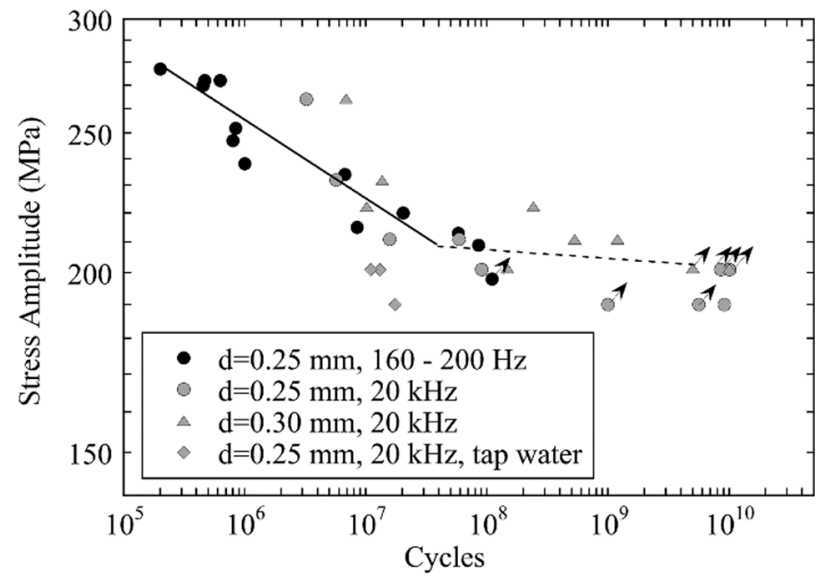

Figure 8. Fatigue data of tubes made of austenitic stainless steel AISI 904L measured with rotating bending at $160 \mathrm{~Hz}-200 \mathrm{~Hz}$ and ultrasonic fatigue equipment at $20 \mathrm{kHz}$; adapted with permission from John Wiley and Sons [49].

In contrast to the fcc austenite, it is well known that a body-centred cubic (bcc) ferritic microstructure exhibits strain-rate dependent mechanical properties $[7,8]$. Not only yield and tensile strength increase with a higher strain rate [51] but also the fatigue properties are exaggerated at higher testing frequencies. Frequency effects in low carbon steels, 
where fatigue crack initiation occurs in the ferrite phase, were systematically investigated by Tsutsumi et al. [52] employing conventional tension-compression tests at $10 \mathrm{~Hz}$ and ultrasonic-fatigue testing. As shown in Figure 9, fatigue lifetimes and fatigue limit were increased at $20 \mathrm{kHz}$ for both annealed (Vickers hardness of $H V=123$ ) and $10 \%$ pre-strained $(H V=160)$ specimens. This was explained by larger cyclic yield stress and a reduction in plastic zone size at the crack tip in ultrasonic fatigue tests [52]. The latter was corroborated by the observation of abundant slip bands around fatigue cracks under conventional fatigue tests that were rarely visible after ultrasonic fatigue testing (Figure 9).
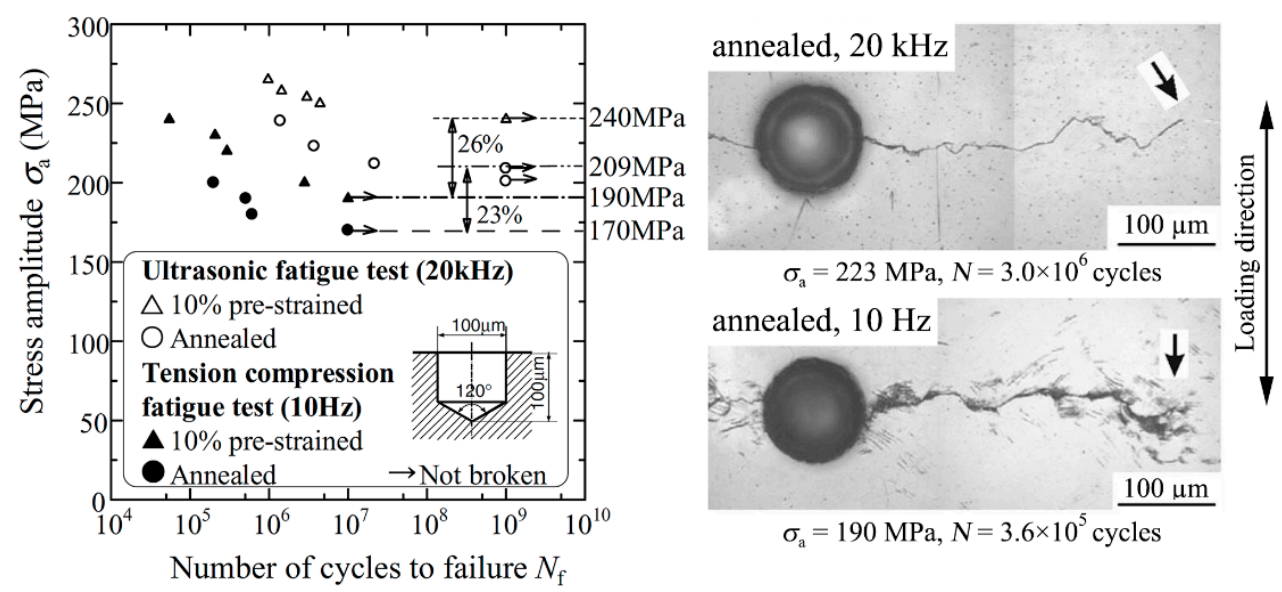

Figure 9. Servo-hydraulic and ultrasonic tension-compressions fatigue test results with annealed and $10 \%$ pre-strained low carbon steel specimens containing 1-hole defects; reprinted with permission from John Wiley and Sons [52].

Extended fatigue lifetimes in ultrasonic fatigue tests were reported in several investigations of mild steels [53-55], and the strain rate sensitivity of ferrite, decreased plastic deformation at high strain rates and retardation in crack formation in the bcc phase are held responsible. Attempts have been made to consider the strain rate sensitivity of ferrite in the presentation of ultrasonic fatigue data. It has been shown [55] that if lifetimes are presented versus normalised stress amplitudes, i.e., the ratio of stress amplitude and tensile strength at room temperature (conventional testing) and the ratio of stress amplitude and tensile strength at $350{ }^{\circ} \mathrm{C}$ (ultrasonic testing), low and high-frequency data show good agreement. Other investigations [56,57] have considered ways to control the fatigue tests, i.e., that ultrasonic experiments are displacement controlled whereas servo-hydraulic tests are force controlled. Considering the strain rate dependence of yield strength, ultrasonic stresses are re-calculated using the cyclic stress-strain curve, which then leads to a good agreement between conventional and ultrasonic fatigue data.

Surprising observations were recently made with the martensitic stainless steels 174PH: while no frequency effects were apparent from the results obtained by servo-hydraulic tension-compression, rotating-bending or ultrasonic fatigue testing $[41,58]$, fatigue lifetimes were significantly prolonged under cyclic torsional loading at ultrasonic frequencies [59] (Figure 10). This can be explained by the presence of elongated $\delta$ ferrite grains where shear cracks can more easily initiate under low-frequency cycling due to the strain-rate sensitivity of the bcc microstructure. Under uniaxial and rotating bending loading, $\delta$ ferrite grains were oriented parallel to the maximum principal stress direction. In this case, the relevant grain size is similar to the diameter of non-metallic inclusions, and failure was more likely to occur from the latter [41], regardless of the testing frequency. Under torsional loading, however, $\delta$ ferrite grains were inclined by approximately $45^{\circ}$ to the direction of the major principal stress and, thus, were oriented parallel to the maximum shear direction. This facilitated the initiation of shear cracks with a length exceeding the size of inherent defects, such as inclusions of uncritical size. As shown in Figure 10, the influence of testing frequency under torsional loading disappeared when artificial defects larger than a critical size were introduced in the test specimens. 


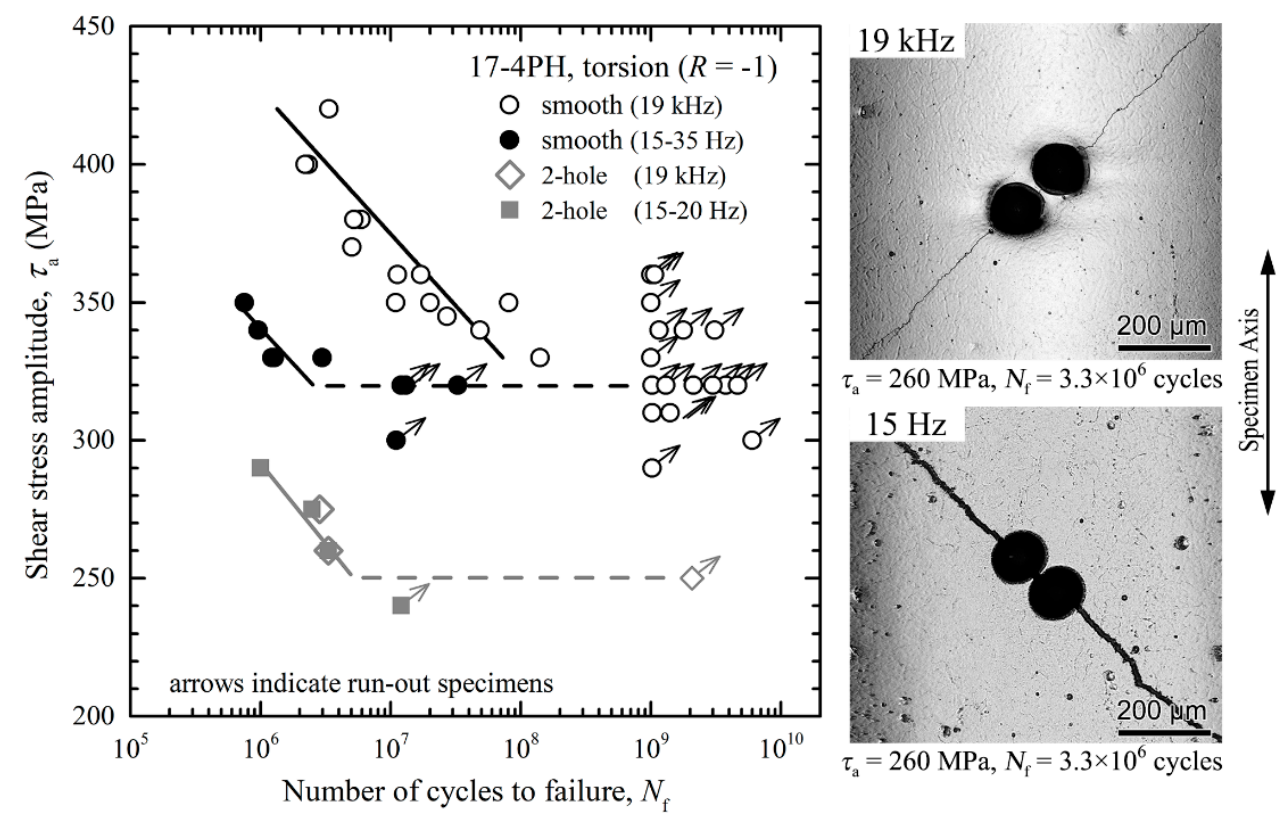

Figure 10. Servo-hydraulic and ultrasonic torsional fatigue tests with martensitic stainless steel 17-4PH (smooth and 2-hole defect containing specimens) [59].

Based on these research results it can be concluded that frequency effects can be neglected if non-metallic inclusions or other defects are the origins of the fatigue fracture. Small defects are the source of the fatigue fracture in high-strength steels and determine their cyclic strength [60]. Several ultrasonic and conventional investigations of the HCF and the VHCF regimes have shown the absence of a frequency effect. A strong size effect due to the increasing probability of encountering large defects with increasing testing volumes must be considered when comparing fatigue data measured with different methods. If the fatigue cracks in steels initiate in a ferritic phase, however, higher fatigue limits and lifetimes are observed in ultrasonic fatigue experiments due to the strain-rate sensitivity of the bcc microstructure. This leads to reduced plastic deformation, a prolonged crack initiation period and an extended crack propagation period. In special cases, this effect may even be relevant in high-strength steels, for example, if ferritic grains are embedded in a martensitic matrix and if they are of sufficient size in the maximum shear direction. In austenitic stainless steels, no frequency effects are expected due to the fcc microstructure. However, comparative tests with conventional and ultrasonic fatigue tests with austenitic steels are limited, and further investigations are necessary.

\subsection{Titanium Alloys}

Titanium alloys are commonly used in aerospace industries, where their high strength and relatively low weight allow for significant weight savings. The additional high corrosion resistance makes them favourable for applications where good performance under high frequencies and at high numbers of load cycles regime is required. HCF-related gas turbine engine failures observed by the US Air Force led to increased interest in fatigue of Ti6Al4V in the early 1990s, resulting in the "High Cycle Fatigue Science And Technology Program" by the US Air Force, starting in 1994 (e.g., [61]). Today, the interest in titanium alloys extends to additively manufactured (AM) applications, where a methodology for the rapid characterisation of fatigue properties for the many different processes, build conditions and post-processing procedures could greatly speed up material development.

Several studies investigated the fatigue performance of Ti6Al4V at $R=-1$ with conventional and ultrasonic fatigue (Figure 11). Generally, wrought Ti6Al4V tested in a high vacuum showed the best performance followed by wrought Ti6Al4V tested in ambient air. The HIPed AM specimens had shown fatigue performance as good as the wrought 
material and even better than cast material. Finally, non-HIPed AM specimens showed the poorest fatigue performance. As-built electron beam melting (EBM) processed specimens and selective laser melting (SLM) processed and heat-treated specimens showed almost equal fatigue performance, since they have been shown to be similar in terms of defect sizes and distribution.

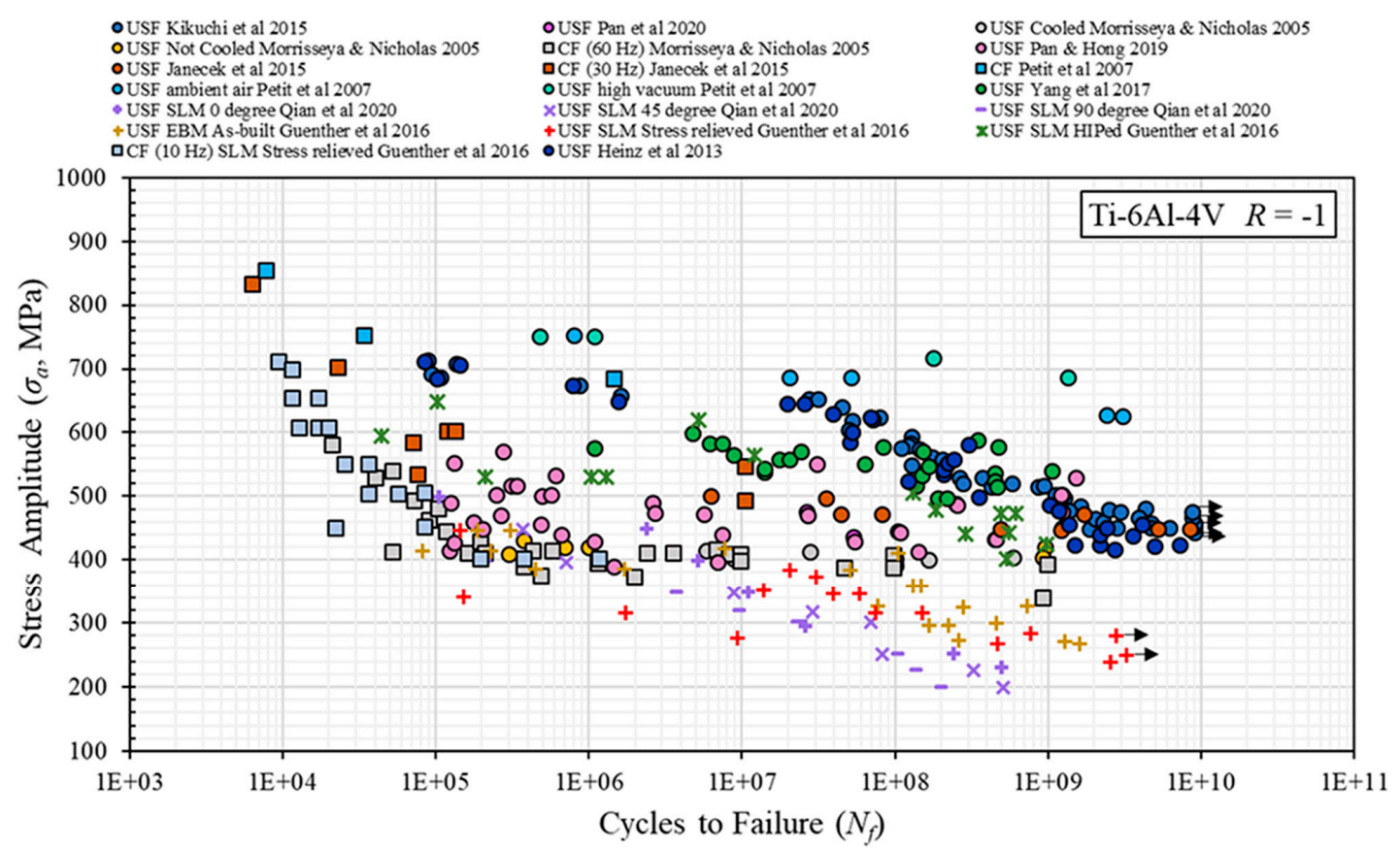

Figure 11. Fatigue data for Ti6Al4V across numerous investigations, generated by conventional and ultrasonic fatigue testing at $R=-1[62-71]$.

Most studies, however, only present either data produced with the conventional testing technique or data from ultrasonic tests, respectively (Figure 11). Direct comparison between conventional and ultrasonic fatigue data across different investigations is not possible, due to the large number of stock material conditions (cast, wrought, AM), heat treatments (affecting, e.g., primary $\alpha$ grain sizes), testing methodologies and specimen geometries. This makes it difficult to draw meaningful conclusions regarding only the effect of testing frequency. It is necessary to test material of the same lot with the same gauge section geometry in both conventional and ultrasonic equipment to only look at the effect of test frequency.

The authors measured the fatigue performance of mill annealed Ti6Al4V using both servo-hydraulic and displacement-controlled ultrasonic fatigue testing equipment. Specimens from the same stock with identical geometry (Figure 1) and identical surface preparation were fatigued in ambient air $\left(24^{\circ} \mathrm{C}, \mathrm{RH} 50 \%\right)$ at $R=0.1$ at $55 \mathrm{~Hz}$ cycling frequency (servo-hydraulic, force-controlled) and $\sim 20 \mathrm{kHz}$ (ultrasonic, displacement controlled), respectively. The resulting lifetimes are shown in Figure 12. Nine samples were cycled with servo-hydraulic equipment with stress amplitude, $\sigma_{\mathrm{a}}$ between $350 \mathrm{MPa}$ and $400 \mathrm{MPa}$, and eight samples with ultrasonic equipment between $290 \mathrm{MPa}$ and $375 \mathrm{MPa}$. For $350 \mathrm{MPa}$ and $375 \mathrm{MPa}$, lifetimes measured with both methods are available. Measured lifetimes were very similar, i.e., the mean lifetimes only deviate by factor 1.1. Assuming a log-normal distribution of cycles to failure, lifetimes for $90 \%$ failure probability were a factor 2.2 higher than for $10 \%$ fracture probability for ultrasonic and servo-hydraulic tests. Approximating data with a power fit, a mean lifetime of $10^{7}$ cycles was found at $\sigma_{\mathrm{a}}=359.7 \mathrm{MPa}$ for servohydraulic and $\sigma_{\mathrm{a}}=356.3 \mathrm{MPa}$ for ultrasonic tests, respectively, i.e., the difference is less than $1 \%$. Thus, the deviation of mean lifetimes measured in ultrasonic and servo-hydraulic tests is much smaller than the scatter of lifetimes, and no statistically significant deviation of lifetimes is found. 


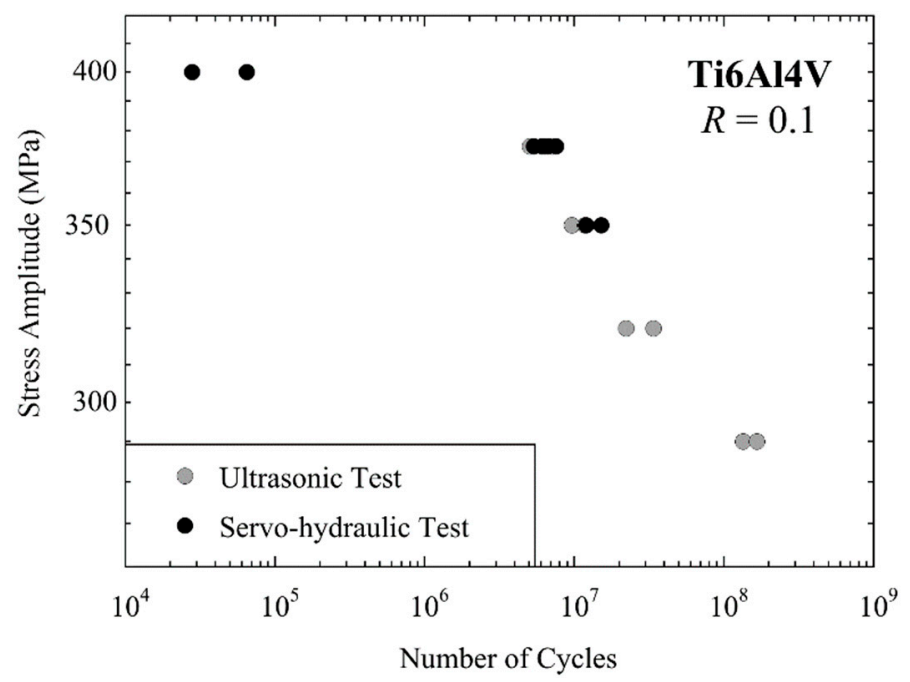

Figure 12. Fatigue data of Ti6Al4V ELI (mill annealed) measured at $R=0.1$ with servo-hydraulic equipment at $55 \mathrm{~Hz}$ cycling frequency (black) and with ultrasonic equipment at $20 \mathrm{kHz}$ (grey).

The fractographic investigation confirmed similar surface morphologies for both testing series: Figure 13 shows fracture surfaces of specimens that were cycled at $\sigma_{\mathrm{a}}=350 \mathrm{MPa}$ and that failed at approximately $10^{7}$ cycles. Both consistently show agglomerations of primary $\alpha$ grains at the crack initiation locations in the back-scatter images (right column). There the material is weakened due to the softer $\alpha$ phase, and cracks are preferentially initiated.
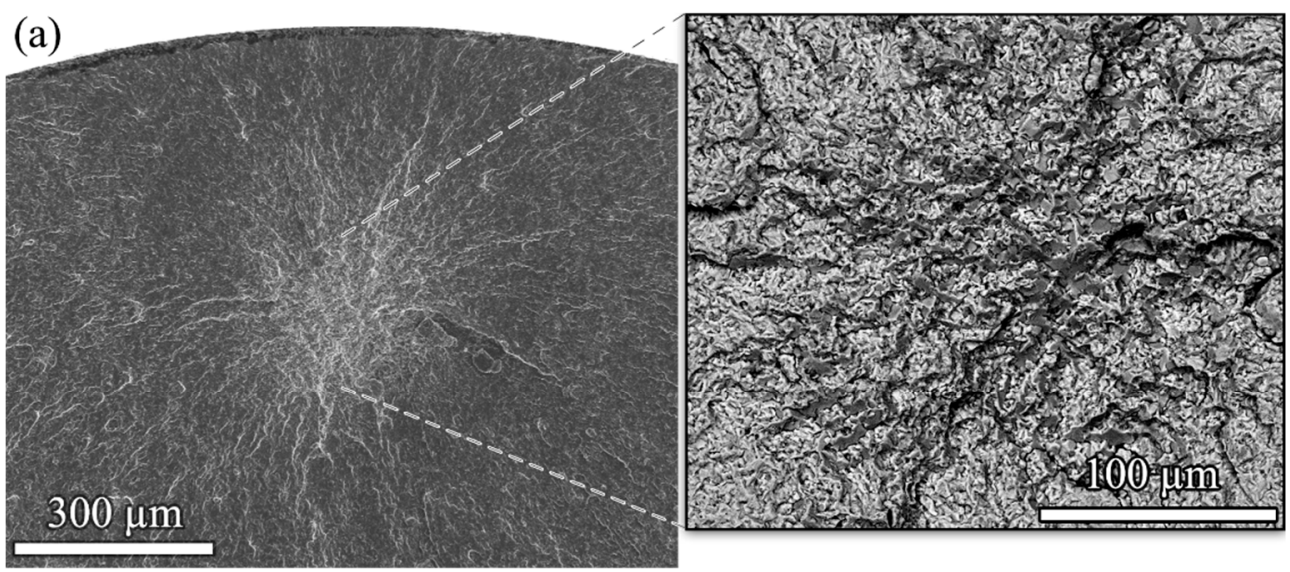

(b)
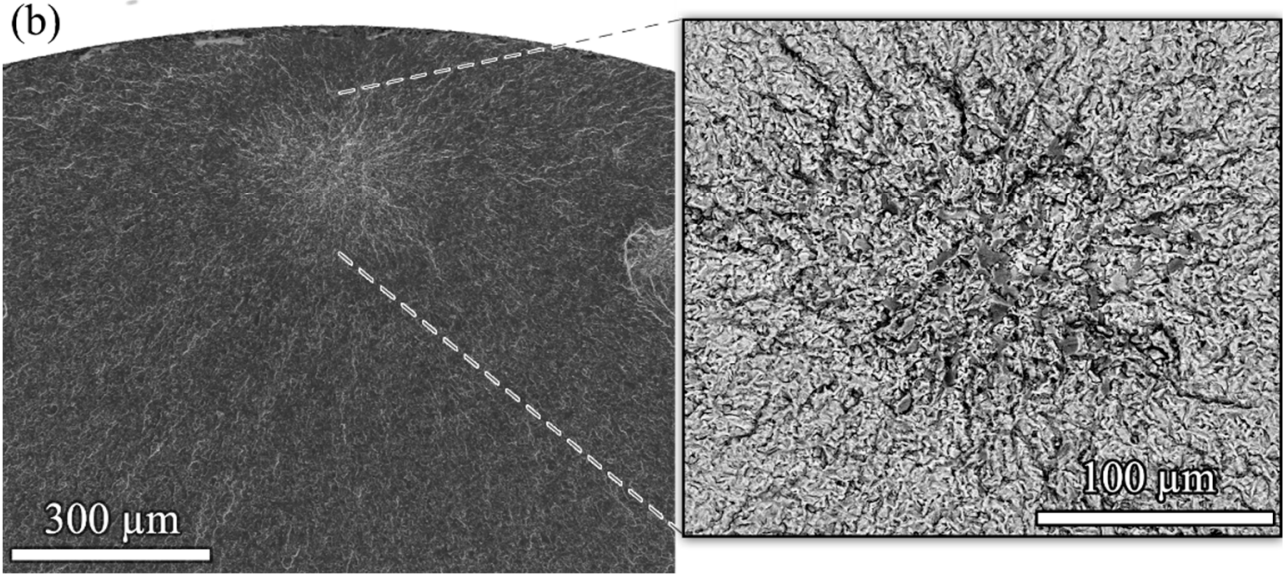

Figure 13. Fracture surfaces from specimens that were cycled at $\sigma_{\mathrm{a}}=350 \mathrm{MPa}$; at (a) $20 \mathrm{kHz}$, $N_{\mathrm{f}}=1.18 \times 10^{7}$ and at $(\mathbf{b}) 55 \mathrm{~Hz}, N_{\mathrm{f}}=1.51 \times 10^{7}$. 
The Ti6Al4V fatigue data from the literature verify these findings. Morrissey and Nicholas [63,72] performed fully reversed fatigue tests with Ti6Al4V (tensile strength $968 \mathrm{MPa}$ ) with servo-hydraulic equipment at $60 \mathrm{~Hz}$ and with ultrasonic equipment at $20 \mathrm{kHz}$. S-N data are available from both testing methods in a wide range between $3 \times 10^{5}$ and $10^{8}$ cycles. Very consistent lifetimes were found at both frequencies, indicating that no frequency influence is present in the investigated conditions.

Similarly, Takeuchi et al. [73] tested Ti6Al4V from three different manufacturers (tensile strengths between $906 \mathrm{MPa}$ and $967 \mathrm{MPa}$; all three heats satisfied ASTM specifications) at $120 \mathrm{~Hz}, 600 \mathrm{~Hz}$ and $20 \mathrm{kHz}$ at $R=-1$. Two of the three heats showed internal crack initiation above approximately $5 \times 10^{6}$ cycles. Fatigue lifetimes measured for these two heats showing internal crack initiation in the long lifetime regime were similar for all three testing frequencies. However, the third heat showed solely surface crack initiation and no failures above $5 \times 10^{6}$ cycles as well as the significant effect of the testing method and significantly higher cyclic strength when tested at the higher frequencies.

Furuya and Takeuchi [74] studied Ti6Al4V from the same three suppliers at $R=0$ and $R=0.3$ as well as with fixed maximum stress and cycling frequencies of $120 \mathrm{~Hz}$ and $20 \mathrm{kHz}$. With superimposed tensile mean loads, all three heats showed failures above $5 \times 10^{6}$ cycles with crack initiation in the interior. No effect of the cycling frequency was found in the $\mathrm{HCF}$ and VHCF regimes for nine testing series overall.

Günther et al. [67] investigated the impact of EBM and SLM additive manufacturing on the fatigue life of Ti6Al4V in the HCF and VHCF regimes. Cylindrical fatigue specimens in differently post-treated conditions were tested at $10 \mathrm{~Hz}$ with servo-hydraulic equipment and at $20 \mathrm{kHz}$ using ultrasonic equipment. Data from the SLM batch shows that the lifetimes and failure modes (i.e., crack initiation locations) are closely similar for both testing methods.

The fatigue properties of laser-additive manufactured Ti6Al4V were investigated by Wycisk et al. [75]. Specimens in stress relieved as well as HIPed conditions were analysed for crack initiation site, mean stress sensitivity and overall fatigue performance. Fatigue tests in tension-compression loading at $59 \mathrm{~Hz}$ and $20 \mathrm{kHz}$ in the HCF and VHCF regimes until $10^{9}$ cycles revealed a clear shift of crack initiation from surface to internal initiation with increasing cycles to failure, regardless of the testing principle. They also stated that no effects of test frequency on life span could be determined.

Other than Ti6Al4V, Papakyriacou et al. [76] tested Ti6Al7Nb that is used for medical applications, with rotating bending equipment at $100 \mathrm{~Hz}$ and with ultrasonic equipment at $20 \mathrm{kHz}$. Fatigue lifetimes between $10^{5}$ and $2 \times 10^{8}$ cycles were measured with both methods, and no frequency effect on fatigue lifetimes was found for this alloy.

Szczepanski et al. [77] characterised the fatigue behaviour of the alpha-beta titanium alloy Ti6Al2Sn4Zr6Mo in the HCF regime using conventional testing at $20 \mathrm{~Hz}$ and in the VHCF regime using ultrasonic equipment at $20 \mathrm{kHz}$, respectively, at a load ratio of 0.05 . The lifetimes they found in both testing series showed a clear separation between earlier failures with crack initiation at the surface and longer lifetimes with crack initiation occurring below the surface. They concluded that, even though the stress levels of the employed testing methods do not overlap, the data follow the same trend as expected for a typical $S-N$ curve. Together with a similar fractographic appearance, the authors interpret this as an indication that there is no appreciable frequency effect on fatigue lifetime between testing frequencies of $20 \mathrm{kHz}$ and $20 \mathrm{~Hz}$ in the investigated Ti6Al2Sn4Zr6Mo alloy.

These results show that titanium alloys may be considered insensitive to frequency effects. Similar lifetimes are found with conventional and ultrasonic equipment, and crack initiation occurs preferentially in the interior at $\alpha$ grains in the VHCF regime for both low and high-frequency testing. The absence of a frequency effect may be expected, irrespective of the way titanium alloys are produced. However, the actual production process of a given titanium alloy can strongly affect the microstructure and consequently the measured fatigue properties. 


\subsection{Nickel Alloys}

Components made of nickel-based superalloys such as turbine blades are typically exposed to a very high number of load cycles, and investigations of the VHCF regime are, therefore, of major importance. In the absence of detrimental defects, e.g., process-related flaws, such as casting pores or lack of fusion, polycrystalline nickel-based alloys typically fail due to favourably oriented large grains located at the surface or in the interior $[78,79]$.

Stöcker et al. [80] performed fatigue tests with nickel alloys over a wide range of lifetimes, from low cycle fatigue to very high cycle fatigue, and obtained a single curve (Figure 14). Other investigations using ultrasonic fatigue testing similarly showed no frequency effect $[81,82]$. Due to their practical importance for gas turbine engines, the hightemperature fatigue properties of nickel alloys are important. This led to interesting further developments of the ultrasonic fatigue testing technique to be used up to $1000{ }^{\circ} \mathrm{C}[82,83]$.
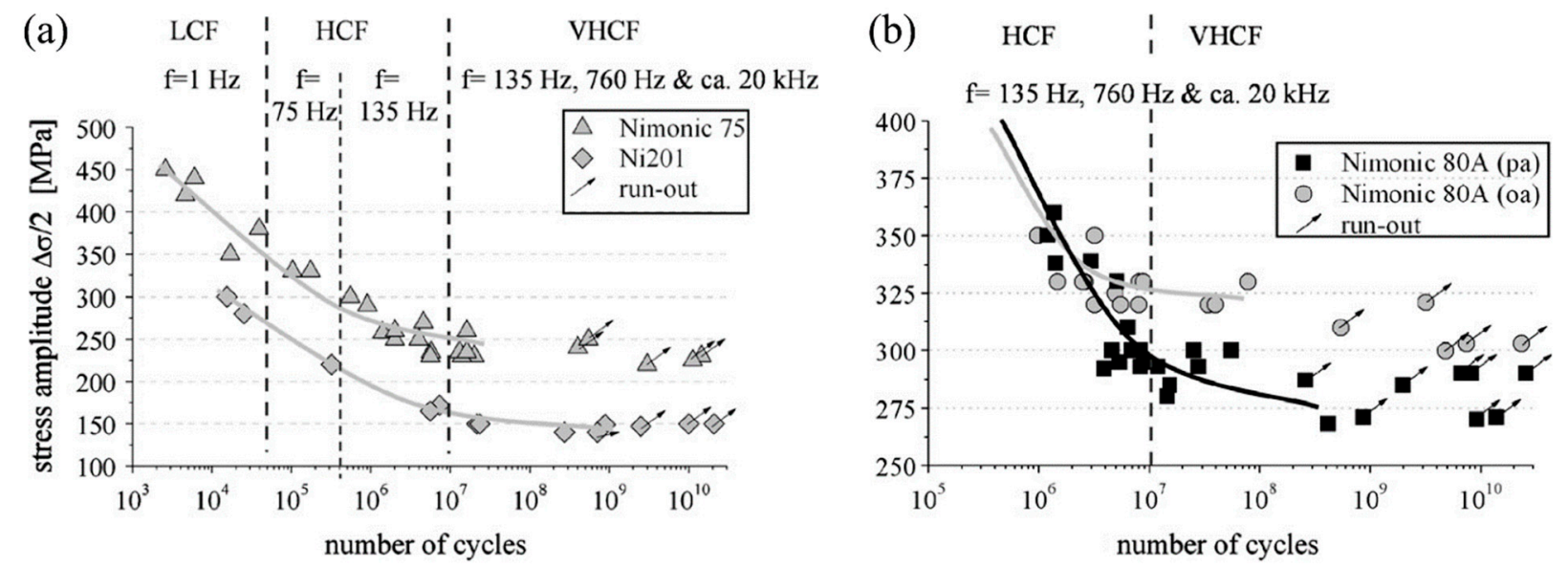

Figure 14. Fatigue data of different Ni-based alloys obtained with servo-hydraulic, resonance electromechanical and ultrasonic fatigue testing; (a) pure nickel (Ni201), Nimonic 75 and (b) peak-aged (pa) and overaged (oa) Nimonic 80A; reprinted with permission from Elsevier [80].

\subsection{Magnesium Alloys}

The three high-pressure die-cast magnesium alloys AZ91 hp, AM60 hp and AE42 hp, were investigated using ultrasonic equipment and servo-hydraulic equipment [18]. As an example, Figure 15 shows the fatigue data of AE42 hp measured with both methods. Fatigue cracks initiate at shrinkage and gas porosity in these high-pressure die-cast materials. Fatigue lifetimes show pronounced scatter due to the different sizes of crack-initiating defects in the different specimens. Within the ranges of scatter, similar lifetimes were measured for the three alloys at both $50 \mathrm{~Hz}$ and $20 \mathrm{kHz}$, respectively. Non-propagating cracks were found at porosities in runout specimens. Porosity can be considered an initial crack, and the fatigue limit can be correlated with the minimum stress intensity factor required to propagate the crack to fracture [18].

\subsection{Fibre-Reinforced Polymers Composites}

The number of applications of polymers and their fibre-reinforced composites has been growing rapidly during the past few decades, due to their low density, excellent chemical resistance, design flexibility, ease of manufacturing and robust mechanical properties. Such materials are used in the aerospace and automotive industries where components may be subjected to high numbers of load cycles. However, cyclic properties of fibrereinforced polymer composites (FRPC) are mostly investigated in the regime below $10^{6}$ cycles. Except for ultrasonic studies, only one gigacycle fatigue investigation can be found in the literature where a carbon fibre-reinforced composite was tested with a resonance tester [84]. VHCF investigations with conventional methods are time-consuming, and therefore attempts have been made to use ultrasonic equipment for fatigue testing of FRPC. 
This is challenging due to the viscoelasticity of polymers and the associated heat generation at ultrasonic frequencies. Due to the low thermal conductivity coefficient of polymers $(\sim 0.2-0.5 \mathrm{~W} / \mathrm{m} / \mathrm{K})$ compared to metals $(\sim 20-300 \mathrm{~W} / \mathrm{m} / \mathrm{K})$, great care must be taken to avoid excessive heating during high-frequency cycling.

Testing glass fibre-reinforced polymer (GFRP) in pulsed mode, with forced air-cooling and with control of specimen surface temperature, it was shown that ultrasonic fatigue testing could be an appropriate technique for gathering valid fatigue data of FRPC [85]. Ultrasonic tests were performed with a static load superimposed to the resonance vibration to realise load ratio $R=0.1$. Figure 16 shows the results of ultrasonic and servo-hydraulic fatigue tests of quasi-unidirectional GFRP ( $90 \%$ of the fibres aligned in the main direction while $10 \%$ of them are woven transversally for stabilisation) with a fibre volume fraction of $60 \%$. Fatigue strengths measured with both techniques agree well, which indicates the suitability and reliability of the developed ultrasonic testing method.

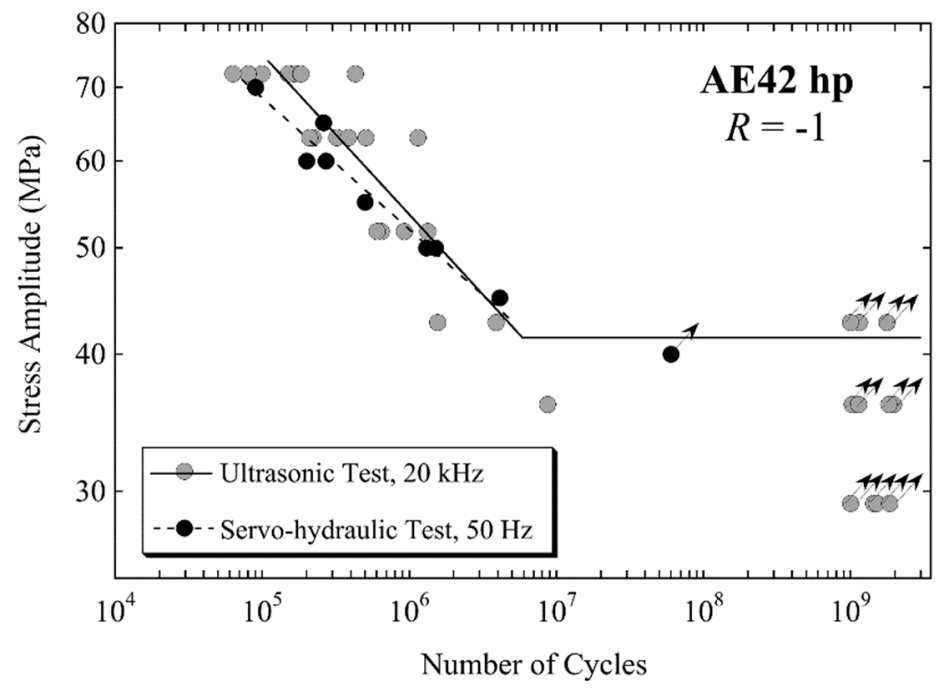

Figure 15. Fatigue data of magnesium alloy AE42 hp produced by high-pressure die-casting; data measured with servo-hydraulic (black circles) and ultrasonic equipment (grey circles) are shown; adapted with permission from Elsevier [18].

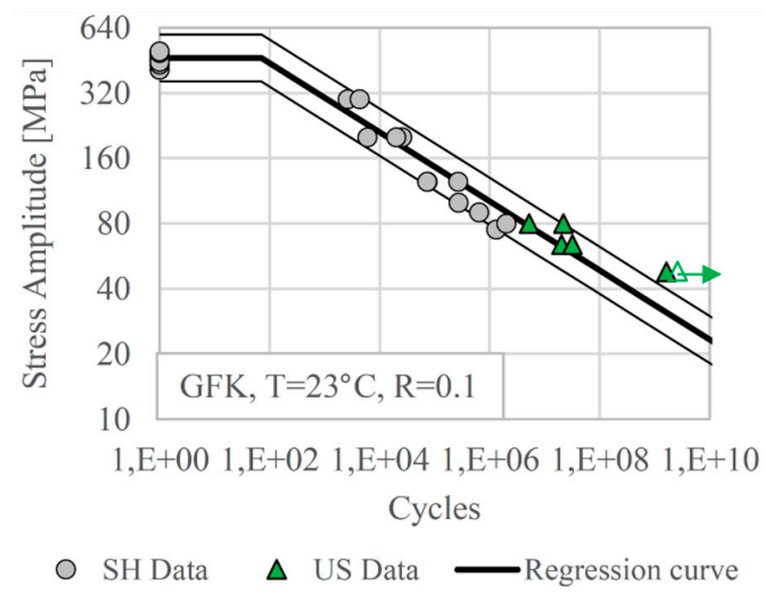

Figure 16. Fatigue data of a quasi-unidirectional glass fibre-reinforced polymer measured at load ratio $R=0.1$ with servo-hydraulic equipment at $10 \mathrm{~Hz}$ and ultrasonic equipment at $20 \mathrm{kHz}$; reprinted with permission from Elsevier [85].

Cyclic properties of GFRP were also studied by Lee et al. [86] using ultrasonic and hydraulic equipment working at $3 \mathrm{~Hz}$, respectively. Tests were performed under fully reversed loading conditions, and shorter lifetimes were found in the ultrasonic tests. Since 
the results of ultrasonic tests are influenced by numerous parameters (e.g., calibration procedure, calculation of cyclic stress amplitude, the accuracy of equipment, the temperature of the specimen) and different specimen shapes were used in low and ultrasonic tests, a number of reasons for shorter lifetimes other than the frequency are possible.

Several ultrasonic studies showed the benefits of high-frequency testing for understanding the process of fatigue damage in FRPCs in the HCF and VHCF regimes. A three-point bending setup, where a specimen was stimulated to bending resonance vibrations at ultrasonic frequencies, was used by Backe et al. $[12,87]$ to investigate the VHCF properties of carbon fibre-reinforced polymer (CFRP). These studies demonstrated the progress of fatigue damage as a multi-stage process starting with the debonding of fibre and matrix, then initiation of transverse cracks in the $90^{\circ}$ layers, micro delamination between $0^{\circ}$ and $90^{\circ}$ fibre roving, followed by macro delamination and finally fracture. Cui et. al. [88] performed similar three-point bending ultrasonic tests of CFRP and showed differences in failure form in the low, high and very high cycle fatigue regime. Ding and Cheng studied the benefit of incorporating nano-silica [89] and multiwall carbon nanotubes [90] into carbon fibre-reinforced composites and reported great improvement in mechanical properties and fatigue resistance of composite materials in presence of nanoparticles.

\subsection{Graphite}

Fatigue properties of isotropic polycrystalline porous graphite (mean grain size $10 \mu \mathrm{m}$, porosity $13 \mathrm{vol} \%$ ) were investigated in the regime between $10^{3}$ and $10^{9}$ cycles. Cyclic tension-compression tests with ultrasonic equipment at $20 \mathrm{kHz}$ and fully-reversed cyclic bending tests at $25 \mathrm{~Hz}$ were performed [91]. The tensile strength of graphite is lower than its bending strength. Comparing the results of both testing series, this is considered by presenting lifetimes versus normalised stress amplitudes. The normalised stress amplitude is the ratio of tension-compression stress amplitude and tensile strength in ultrasonic tests, and the ratio of bending stress amplitude and bending strength in cyclic bending tests.

Figure 17 shows fatigue lifetimes of graphite measured at $25 \mathrm{~Hz}$ and $20 \mathrm{kHz}$. Ultrasonic fatigue data are slightly shifted towards higher lifetimes compared with cyclic bending data; however, this difference is well within the range of scatter. It can be concluded, therefore, that the ultrasonic testing technique is appropriate for the rapid collection of fatigue data of graphite. Moreover, ultrasonic fatigue testing was also used to demonstrate the beneficial effect of infiltration of graphite with AlSi7Mg alloy cyclic strength [91].

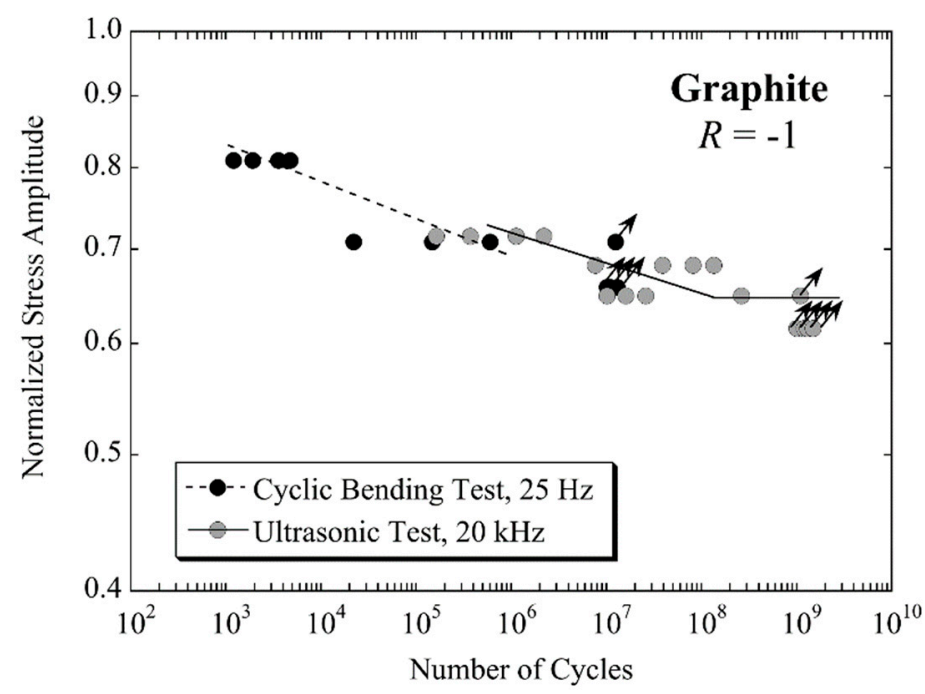

Figure 17. Fatigue data of polycrystalline graphite measured under fully reversed loading condition for cyclic bending (black circles) and ultrasonic tension-compression loading (grey circles), respectively; fatigue lifetimes are presented versus normalised stress amplitudes; adapted with permission from Elsevier [91]. 


\subsection{Other Materials}

In addition to the aforementioned material systems, several others have been successfully tested with ultrasonic equipment.

Fatigue crack initiation, slow crack propagation and conditions for crack arrest were studied in the aluminium laminates ARALL [92] and GLARE [93]. These materials are used in aerospace applications, where crack initiation at notches and slow fatigue crack growth are of great practical interest. Particularly, GLARE with glass fibres preloaded in the tension demonstrated strongly improved cyclic properties compared to aluminium alloy laminates [93].

In a specifically developed setup, thin wires $(\varnothing 0.1 \mathrm{~mm})$ of the high-entropy alloy CoNiCr alloy MP35N were tested in the VHCF regime [94]. In this special application, the wire specimen does not vibrate in resonance, but is cyclically stressed in a quasi-static fashion at ultrasonic frequencies. The usability of the newly developed method was demonstrated by measuring lifetimes that are comparable to conventional tests [94].

Cyclic compression loading was purpose-developed for VHCF testing of concrete. With this technique, the damage mechanism in the very long lifetime regime could be demonstrated for concrete used in wind power plant foundations [95].

Fundamental studies on the fatigue mechanisms have been extensively performed with pure copper. It was shown, for example, that new persistent slip bands are formed even after $5 \times 10^{8}$ cycles [96].

Phase transformation and associated fatigue damage were studied in the shape memory alloy Nitinol [97]. In situ synchrotron experiments successfully demonstrated the occurrence of the forward and reverse transformation between the material's austenitic and martensitic phases in a super elastic state at ultrasonic frequencies.

\section{Conclusions}

Based on the literature and original data, this paper summarises the current understanding of whether and how fatigue properties measured with ultrasonic and conventional equipment are comparable.

- While the orders of magnitude are faster than conventional fatigue testing, no generally accepted standard for ultrasonic fatigue testing exists. The use of equipment with closed-loop control of vibration amplitude and the resonance frequency is strongly advised since this guarantees high accuracy and reproducibility of ultrasonic tests. Pulsed loading and appropriate cooling are necessary to avoid specimen heating.

- Depending on the material, frequency influences can be caused by strain rate influences on plastic deformation, and by time-dependent influences of the testing environment. The size effect must be considered for all materials, if low and ultrasonic frequency data are compared.

- Several aluminium alloys show comparable lifetimes in ultrasonic and conventional tests. Some alloys tested in ambient air show prolonged lifetimes at high frequency, due to a reduced influence of air humidity. Ultrasonic tests in high humidity or in distilled water can better approximate the environmental conditions acting at low cycling frequencies.

- Frequency effects can be neglected in high-strength steels, where non-metallic inclusions or other defects are preferential crack initiation locations in the regime of long lifetimes. Ultrasonic tests of steels lead to prolonged lifetimes if fatigue cracks initiate in a ferritic phase. Austenitic stainless steels are less prone to frequency effects.

- Titanium alloys may be considered insensitive to frequency effects, as suggested by data from both the original work and the literature. Similar lifetimes and similar crack initiation locations are found with conventional and ultrasonic equipment.

- Ultrasonic tests with nickel alloys showed no frequency effect. On the basis of limited data, the same conclusion can be drawn for cast magnesium alloys and graphite.

- Ultrasonic tests of a glass fibre-reinforced polymer delivered comparable fatigue lifetimes to servo-hydraulic tests, i.e., high-frequency testing is in principle applicable 
to testing fibre-reinforced polymer composites. However, further research is needed to better understand the influence of the experimental procedure on the measured data.

Author Contributions: M.F.: methodology, formal analysis, validation, investigation, data curation, writing-original draft, visualization; B.M.S.: formal analysis, data curation, writing-original draft, visualization; R.K.R.: data curation, writing-review and editing; N.S.: data curation, writingreview and editing, visualisation; S.Z.: data curation, writing-review and editing; S.A.T.: supervision, funding acquisition, writing - review and editing; J.W.C.: supervision, funding acquisition; H.M.: conceptualisation, methodology, formal analysis, writing-original draft, supervision, project administration. All authors have read and agreed to the published version of the manuscript.

Funding: This research received no external funding.

Institutional Review Board Statement: Not applicable.

Informed Consent Statement: Not applicable.

Data Availability Statement: The data are not publicly available as further investigations are currently ongoing.

Acknowledgments: We would like to pay our gratitude and our respects to our late colleague G. Pfersmann, who has worked with us for many years and who is, in large, responsible for the design, development and realisation of the ultrasonic fatigue testing equipment at BOKU. Without him, this and many preceding works would not have been possible.

Conflicts of Interest: The authors declare no conflict of interest.

\section{References}

1. Stanzl-Tschegg, S. Very high cycle fatigue measuring techniques. Int. J. Fatigue 2014, 60, 2-17. [CrossRef]

2. Willertz, L.E. Ultrasonic Fatigue. Int. Met. Rev. 1980, 2, 65-78.

3. Roth, L.D. Ultrasonic Fatigue Testing. In ASM Handbook; Newby, J.R., Davis, J.R., Refsnes, S.K., Dietrich, D.A., Eds.; ASTM: Philadelphia, PA, USA, 1992; Volume 8, pp. 240-258.

4. Mayer, H. Fatigue crack growth and threshold measurements at very high frequencies. Int. Mater. Rev. 1999, 44, 1-36. [CrossRef]

5. Mayer, H. Recent developments in ultrasonic fatigue. Fatigue Fract. Eng. Mater. Struct. 2016, 39, 3-29. [CrossRef]

6. Standards, T.J.W.E. Standard Method for Ultrasonic Fatigue Test in Metallic Materials; The Japan Welding Engineering Society Standards: Tokyo, Japan, 2017; Volume WES 1112.

7. Laird, C.; Charsley, P. Strain Rate Sensitivity Effects in Cyclic Deformation and Fatigue Fracture. In Ultrasonic Fatigue (Proc. 1st Int. Conf. on Fatigue and Corrosion Fatigue Up to Ultrasonic Frequencies); Wells, J.M., Buck, O., Roth, L.D., Tien, J.K., Eds.; Transactions of the Metallurgical Society of AIME: Philadelphia, PA, USA, 1982; pp. 187-205.

8. Mughrabi, H.; Herz, K.; Stark, X. Cyclic Deformation and Fatigue Behaviour of a-Iron Mono- and Polycrystals. Int. J. Fract. 1981, 17, 193-220. [CrossRef]

9. Zhu, X.; Jones, J.W.; Allison, J.E. Effect of frequency, environment, and temperature on fatigue behavior of E319 cast aluminum alloy: Stress-controlled fatigue life response. Met. Mater. Trans. A 2008, 39, 2681-2688. [CrossRef]

10. Zhu, X.; Jones, J.W.; Allison, J.E. Effect of frequency, environment, and temperature on fatigue behavior of E319 cast aluminum alloy: Small crack propagation. Met. Mater. Trans. A 2008, 39, 2666-2680. [CrossRef]

11. Sharpe, W.N. A 20 kHz Optical Strain Gauge, 4th ed.; In International Conference on Very High Cycle Fatigue (VHCF-3); Ann, A.M.I., Allison, J.E., Jones, J.W., Larsen, J.M., Ritchie, R.O., Eds.; TMS: Warrendale, PA, USA, 2007; pp. $341-346$.

12. Backe, D.; Balle, F.; Eifler, D. Fatigue testing of CFRP in the Very High Cycle Fatigue (VHCF) regime at ultrasonic frequencies. Compos. Sci. Technol. 2015, 106, 93-99. [CrossRef]

13. Papakyriacou, M.; Mayer, H.; Plenk, H.; Tschegg, S. Cyclic plastic deformation of tantalum and niobium at very high numbers of cycles. Mater. Sci. Eng. A 2002, 325, 520-524. [CrossRef]

14. Zettl, B.; Mayer, H.; Ede, C.; Stanzl-Tschegg, S. Very high cycle fatigue of normalized carbon steels. Int. J. Fatigue 2006, 28, 1583-1589. [CrossRef]

15. Stanzl, S.E.; Tschegg, E.K.; Mayer, H.R. Lifetime Measurements for Random Loading in the Very High Cycle Fatigue Range. Int. J. Fatigue 1986, 8, 195-200. [CrossRef]

16. Fitzka, M.; Pennings, B.; Karr, U.; Schönbauer, B.; Schuller, R.; Tran, M.-D.; Mayer, H. Influence of cycling frequency and testing volume on the VHCF properties of 18Ni maraging steel. Eng. Fract. Mech. 2019, 216, 106525. [CrossRef]

17. Stanzl-Tschegg, S.E.; Mayer, H.R. Fatigue and fatigue crack growth of aluminium alloys at very high numbers of cycles. Int. J. Fatigue 2001, 23, 231-237. [CrossRef]

18. Mayer, H.; Papakyriacou, M.; Zettl, B.; Stanzl-Tschegg, S.E. Influence of porosity on the fatigue limit of die cast magnesium and aluminium alloys. Int. J. Fatigue 2003, 25, 245-256. [CrossRef] 
19. Caton, M.J.; Jones, J.W.; Mayer, H.; Stanzl-Tschegg, S.; Allison, J.E. Demonstration of an Endurance Limit in Cast 319 Aluminum. Met. Mater. Trans. A 2003, 34, 33-41. [CrossRef]

20. Mayer, H.; Schuller, R.; Fitzka, M. Fatigue of 2024-T351 aluminium alloy at different load ratios up to $10^{10}$ cycles. Int. J. Fatigue 2013, 57, 113-119. [CrossRef]

21. Mayer, H.; Fitzka, M.; Schuller, R. Variable amplitude loading of Al 2024-T351 at different load ratios using ultrasonic equipment. Int. J. Fatigue 2014, 60, 34-42. [CrossRef]

22. Fitzka, M.; Mayer, H. Constant and variable amplitude fatigue testing of aluminum alloy 2024-T351 with ultrasonic and servo-hydraulic equipment. Int. J. Fatigue 2016, 91, 363-372. [CrossRef]

23. Mayer, H. Ultrasonic torsion and tension-compression fatigue testing: Measuring principles and investigations on 2024-T351 aluminium alloy. Int. J. Fatigue 2006, 28, 1446-1455. [CrossRef]

24. Mayer, H.; Papakyriacou, M.; Pippan, R.; Stanzl-Tschegg, S. Influence of Loading Frequency on the High Cycle Fatigue Properties of AlZnMgCu1.5 Aluminium Alloy. Mater. Sci. Eng. A 2001, 314, 51-57. [CrossRef]

25. Zettl, B.; Mayer, H.; Stanzl-Tschegg, S.E. Fatigue properties of Al1Mg0.6Si foam at low and ultrasonic frequencies. Int. J. Fatigue 2001, 23, 565-573. [CrossRef]

26. Stanzl-Tschegg, S.E.; Mayer, H.; Schuller, R.; Przeorski, T.; Krug, P. Fatigue properties of spray formed hypereutectic aluminium silicon alloy DISPAL ${ }^{\circledR}$ S232 at high and very high numbers of cycles. Mater. Sci. Eng. A 2012, 538, 327-334. [CrossRef]

27. Awd, M.; Siddique, S.; Johannsen, J.; Emmelmann, C.; Walther, F. Very high-cycle fatigue properties and microstructural damage mechanisms of selective laser melted AlSi10Mg alloy. Int. J. Fatigue 2019, 124, 55-69. [CrossRef]

28. Awd, M.; Siddique, S.; Walther, F. Microstructural damage and fracture mechanisms of selective laser melted Al-Si alloys under fatigue loading. Appl. Fract. Mech. 2020, 106, 102483. [CrossRef]

29. Rhein, R.K.; Shi, Q.; Arjun Tekalur, S.; Wayne Jones, J.; Carroll, J.W. Effect of direct metal laser sintering build parameters on defects and ultrasonic fatigue performance of additively manufactured AlSi10Mg. Fatigue Fract. Eng. Mater. Struct. 2021, 44, 295-305. [CrossRef]

30. Holper, B.; Mayer, H.; Vasudevan, A.K.; Stanzl-Tschegg, S.E. Near Threshold Fatigue Crack Growth in Aluminium Alloys at Low and Ultrasonic Frequency: Influences of Specimen Thickness, Strain Rate, Slip Behaviour and Air Humidity. Int. J. Fatigue 2003, 25, 397-411. [CrossRef]

31. Holper, B.; Mayer, H.; Vasudevan, A.K.; Stanzl-Tschegg, S.E. Near Threshold Fatigue Crack Growth at Positive Load Ratio in Aluminium Alloys at Low and Ultrasonic Frequency: Influences of Strain Rate, Slip Behaviour and Air Humidity. Int. J. Fatigue 2004, 26, 27-38. [CrossRef]

32. Wei, R.P. Rate Controlling Processes and Crack Growth Response. In Hydrogen Effects in Metals; Bernstein, I.M., Thompson, A.W., Eds.; TMS: Warrendale, PA, USA, 1980; pp. 677-689.

33. Wei, R.P.; Pao, P.S.; Hart, G.; Weir, T.W.; Simmons, G.W. Fracture Mechanics and Surface Chemistry Studies of Fatigue Crack Growth in an Aluminium Alloy. Met. Trans. A 1980, 11, 151-185. [CrossRef]

34. Engler-Pinto, C.C.; Frisch, R.J.; Lasecki, J.V.; Mayer, H.; Allison, J.R. Effect of Frequency and Environment on High Cycle Fatigue of Cast Aluminum Alloys, 4th International Conference on Very High Cycle Fatigue; Ann, A.M.I., Allison, J.E., Jones, J.W., Larsen, J.M., Ritchie, R.O., Eds.; TMS: Warrendale, PA, USA, 2007; pp. 421-427.

35. Atrens, A.; Hoffelner, W.; Duerig, T.W.; Allison, J.E. Subsurface crack initiation in high cycle fatigue in Ti6A14V and in a typical martensitic stainless steel. Scr. Met. Mater. 1983, 17, 601-606. [CrossRef]

36. Naito, T.; Ueda, H.; Kikuchui, M. Fatigue behavior of carburized steel with internal oxides and nonmartensitic micro-structure near the surface. Met. Trans. A 1984, 15, 1431-1436. [CrossRef]

37. Asami, K.; Sugiyama, Y. Fatigue strength of various surface hardened steels. J. Heat Treat. Technol. Assoc. 1985, 25, 147-150.

38. Murakami, Y.; Nomotomo, T.; Ueda, T.; Murakami, Y. On the mechanism of fatigue failure in the superlong life regime ( $>10^{7}$ cycles). Part I: Influence of hydrogen trapped by inclusions. Fatigue Fract. Engng. Mater. Struct. 2000, 23, 893-902. [CrossRef]

39. Murakami, Y.; Nomotomo, T.; Ueda, T.; Murakami, Y. On the mechanism of fatigue failure in the superlong life regime (>10 7 cycles). Part II: A fractographic investigation. Fatigue Fract. Eng. Mater. Struct. 2000, 23, 903-910. [CrossRef]

40. Sakai, T.; Sato, Y.; Oguma, N. Characteristic S-N properties of high-carbon-chromium-bearing steel under axial loading in long-life fatigue. Fatigue Fract. Engng. Mater. Struct. 2002, 25, 765-773. [CrossRef]

41. Schönbauer, B.M.; Fitzka, M.; Karr, U.; Mayer, H. Variable amplitude very high cycle fatigue of 17-4PH steel with a stepwise S-N curve. Int. J. Fatigue 2021, 142, 105963. [CrossRef]

42. Furuya, Y.; Hirukawa, H.; Takeuchi, E. Gigacycle fatigue in high strength steels. Sci. Technol. Adv. Mat. 2019, 20, 643-656. [CrossRef] [PubMed]

43. Furuya, Y. Specimen size effects on gigacycle fatigue properties of high-strength steel under ultrasonic fatigue testing. Scr. Mater. 2008, 58, 1014-1017. [CrossRef]

44. Furuya, Y. Notable size effects on very high cycle fatigue properties of high-strength steel. Mater. Sci. Eng. A 2011, 528, 5234-5240. [CrossRef]

45. Li, W.; Sakai, T.; Li, Q.; Luc, L.T.; Wang, P. Effect of loading type on fatigue properties of high strength bearing steel in very high cycle regime. Mater. Sci. Eng. A 2011, 528, 5044-5052. [CrossRef]

46. Kovacs, S.; Beck, T.; Singheiser, L. Influence of mean stresses on fatigue life and damage of a turbine blade steel in the VHCFregime. Int. J. Fatigue 2013, 49, 90-99. [CrossRef] 
47. Schmid, S.; Hahn, M.; Issler, S.; Bacher-Hoechst, M.; Furuya, Y.; Mehner, A.; Bomas, H.; Zoch, H.W. Effect of frequency and biofuel E85 on very high cycle fatigue behaviour of the high strength steel X90CrMoV18. Int. J. Fatigue 2014, 60, 90-100. [CrossRef]

48. Morito, S.; Yoshida, H.; Maki, T.; Huang, X. Effect of block size on the strength of lath martensite in low carbon steels. Mater. Sci. Eng. A 2006, 438-440, 237-240. [CrossRef]

49. Carstensen, J.; Mayer, H.; Bronsted, P. Very high cycle regime fatigue of thin walled tubes made from austenitic stainless steel. Fatigue Fract. Eng. Mater. Struct. 2002, 25, 837-844. [CrossRef]

50. Grigorescu, A.C.; Hilgendorff, P.M.; Zimmermann, M.; Fritzen, C.P.; Christ, H.J. Cyclic deformation behavior of austenitic Cr-Ni-steels in the VHCF regime: Part I-Experimental study. Int. J. Fatigue 2016, 93, 250-260. [CrossRef]

51. Manjoine, M.J. Influence of Rate of Strain and Temperature on Yield Stresses of Mild Steel. J. Appl. Mech. 2021, 11, A211-A218. [CrossRef]

52. Tsutsumi, N.; Murakami, Y.; Doquet, V. Effect of test frequency on fatigue strength of low carbon steel. Fatigue Fract. Eng. Mater. Struct. 2009, 32, 473-483. [CrossRef]

53. Guennec, B.; Ueno, A.; Sakai, T.; Takanashi, M.; Itabashi, Y. Effect of the loading frequency on fatigue properties of JIS S15C low carbon steel and some discussions based on micro-plasticity behavior. Int. J. Fatigue 2014, 66, 29-38. [CrossRef]

54. Nonaka, I.; Setowaki, S.; Ichikawa, Y. Effect of load frequency on high cycle fatigue strength of bullet train axle steel. Int J. Fatigue 2014, 60, 43-47. [CrossRef]

55. Torabian, N.; Favier, V.; Dirrenberger, J.; Adamski, F.; Ziaei-Rad, S.; Ranc, N. Correlation of the high and very high cycle fatigue response of ferrite based steels with strain rate-temperature conditions. Acta Mater. 2017, 134, 40-52. [CrossRef]

56. Geilen, M.B.; Klein, M.; Oechsner, M.; Kaffenberger, M.; Störzel, K.; Melz, T. A method for the strain rate dependent correction for control type of fatigue tests. Int. J. Fatigue 2020, 138, 105726. [CrossRef]

57. Geilen, M.B.; Schönherr, J.A.; Klein, M.; Leininger, D.S.; Giertler, A.; Krupp, U.; Oechsner, M. On the Influence of Control Type and Strain Rate on the Lifetime of 50CrMo4. Metals 2020, 10, 1458. [CrossRef]

58. Schönbauer, B.M.; Yanase, K.; Endo, M. VHCF properties and fatigue limit prediction of precipitation hardened 17-4PH stainless steel. Int. J. Fatigue 2016, 88, 205-216. [CrossRef]

59. Schönbauer, B.M.; Yanase, K.; Chehrehrazi, M.; Endo, M.; Mayer, H. Effect of microstructure and cycling frequency on the torsional fatigue properties of 17-4PH stainless steel. Mater. Sci. Eng. A Struct. 2021, 801, 140481. [CrossRef]

60. Murakami, Y. Material defects as the basis of fatigue design. Int. J. Fatigue 2012, 41, 2-10. [CrossRef]

61. Morrissey, R.J.; McDowell, D.L.; Nicholas, T. Frequency and stress ratio effects in high cycle fatigue of Ti-6Al-4V. Int. J. Fatigue 1999, 21, 679-685. [CrossRef]

62. Kikuchi, S.; Heinz, S.; Eifler, D.; Nakamura, Y.; Ueno, A. Evaluation of Very High Cycle Fatigue Properties of Low Temperature Nitrided Ti-6Al-4V Alloy Using Ultrasonic Testing Technology. Key Eng. Mater. 2016, 664, 118-127. [CrossRef]

63. Morrissey, R.J.; Nicholas, T. Fatigue strength of Ti-6Al-4V at very long lives. Int. J. Fatigue 2005, 27, 1608-1612. [CrossRef]

64. Janecek, M.; Novy, F.; Harcuba, P.; Strasky, J.; Trsko, L.; Mhaede, M.; Wagner, L. The Very High Cycle Fatigue Behaviour of Ti6Al4V Alloy. Acta Phys. Polonica A 2015, 128, 497-502. [CrossRef]

65. Petit, J.; Sarrazin-Baudoux, C.; Martinez, J.; Stanzl-Tschegg, S.; Mayer, H. Very High Cycle Fatigue Behavior of a Ti6246 Alloy in air and In High Vacuum, 4th Internation Conference on Very High Cycle Fatigue; Allison, J.E., Jones, J.W., Larsen, J.M., Ritchie, R.O., Eds.; TMS: Warrendale, PA, USA, 2007; pp. 399-408.

66. Qian, G.; Li, Y.; Paolino, D.S.; Tridello, A.; Berto, F.; Hong, Y. Very-high-cycle fatigue behavior of Ti-6Al-4V manufactured by selective laser melting: Effect of build orientation. Int. J. Fatigue 2020, 136, 105628. [CrossRef]

67. Günther, J.; Krewerth, D.; Lippmann, T.; Leuders, S.; Tröster, T.; Weidner, A.; Biermann, H.; Niendorf, T. Fatigue life of additively manufactured Ti-6Al-4V in the very high cycle fatigue regime. Int. J. Fatigue 2017, 94, 236-245. [CrossRef]

68. Pan, X.; Hong, Y. High-cycle and very-high-cycle fatigue behaviour of a titanium alloy with equiaxed microstructure under different mean stresses. Fatigue Fract. Eng. Mater. Struct. 2019, 42, 1950-1964. [CrossRef]

69. Pan, X.; Qian, G.; Wu, S.; Fu, Y.; Hong, Y. Internal crack characteristics in very-high-cycle fatigue of a gradient structured titanium alloy. Sci. Rep. 2020, 10, 4742. [CrossRef]

70. Heinz, S.; Balle, F.; Wagner, G.; Eifler, D. Analysis of fatigue properties and failure mechanisms of Ti6Al4V in the very high cycle fatigue regime using ultrasonic technology and 3D laser scanning vibrometry. Ultrasonics 2014, 53, 1433-1440. [CrossRef]

71. Yang, K.; He, C.; Huang, Q.; Huang, Z.Y.; Wang, C.; Wang, Q.; Liu, Y.J.; Zhong, B. Very high cycle fatigue behaviors of a turbine engine blade alloy at various stress ratios. Int. J. Fatigue 2017, 99, 35-43. [CrossRef]

72. Morrissey, R.J.; Nicholas, T. Staircase testing of a titanium alloy in the gigacycle regime. Int. J. Fatigue 2006, 28, 1577-1582. [CrossRef]

73. Takeuchi, E.; Furuya, Y.; Nagashima, N.; Matsuoka, S. The effect of frequency on the giga-cycle fatigue properties of a Ti-6Al-4V alloy. Fatigue Fract. Engng. Mater. Struct. 2008, 31, 599-605. [CrossRef]

74. Furuya, Y.; Takeuchi, E. Gigacycle fatigue properties of Ti-6Al-4V alloy under tensile mean stress. Mater. Sci. Eng. A Struct. 2014, 598, 135-140. [CrossRef]

75. Wycisk, E.; Siddique, S.; Herzog, D.; Walther, F.; Emmelmann, C. Fatigue Performance of Laser Additive Manufactured Ti-6Al-4V in Very High Cycle Fatigue Regime up to $10^{9}$ Cycles. Frontiers 2015, 2, 72.

76. Papakyriacou, M.; Mayer, H.; Pypen, C.H.P., Jr.; Stanzl-Tschegg, S. Influence of Loading Frequency on High-Cycle Fatigue Properties of b.c.c. and h.c.p. Metals. Mater. Sci. Eng. A 2001, 308, 143-152. [CrossRef] 
77. Szczepanski, C.J.; Jha, S.K.; Larsen, J.M.; Jones, J.W. Microstructural Influences on Very-High-Cycle Fatigue-Crack Initiation in Ti-6246. Met. Mater. Trans. A 2008, 39, 2841-2851. [CrossRef]

78. Miao, J.; Pollock, T.M.; Wayne Jones, J. Crystallographic fatigue crack initiation in nickel-based superalloy René 88DT at elevated temperature. Acta Mater. 2009, 57, 5964-5974. [CrossRef]

79. Okazaki, S.; Takakuwa, O.; Ogawa, Y.; Okita, K.; Funakoshi, Y.; Yamabe, J.; Matsuoka, S.; Matsunaga, H. Effect of defects on the fatigue limit of Ni-based superalloy 718 with different grain sizes. Fatigue Fract. Eng. Mater. Struct. 2019, 42, $1203-1213$.

80. Stöcker, C.; Zimmermann, M.; Christ, H.-J. Localized cyclic deformation and corresponding dislocation arrangements of polycrystalline Ni-base superalloys and pure Nickel in the VHCF regime. Int. J. Fatigue 2011, 33, 2-9. [CrossRef]

81. Shyam, A.; Torbet, C.; Jha, S.; Larsen, J.; Caton, M.; Szczepanski, C.; Pollock, T.; Jones, J. Development of Ultrasonic Fatigue for Rapid, High Temperature Fatigue Studies in Turbine Engine Materials. Proc. Int. Symp. Superalloys 2004, $259,268$.

82. Cervellon, A.; Cormier, J.; Mauget, F.; Hervier, Z.; Nadot, Y. Very High Cycle Fatigue of Ni-Based Single-Crystal Superalloys at High Temperature. Met. Mater. Trans. A 2018, 49, 3938-3950. [CrossRef]

83. Yi, J.Z.; Torbet, C.J.; Feng, Q.; Pollock, T.M.; Jones, J.W. Ultrasonic fatigue of a single crystal Ni-base superalloy at $1000{ }^{\circ} \mathrm{C}$. Mater. Sci. Eng. A Struct. 2007, 443, 142-149. [CrossRef]

84. Michel, S.A.; Kieselbach, R.; Martens, H.J. Fatigue strength of carbon fibre composites up to the gigacycle regime (gigacyclecomposites). Int. J. Fatigue 2006, 28, 261-270. [CrossRef]

85. Flore, D.; Wegener, K.; Mayer, H.; Karr, U.; Oetting, C.C. Investigation of the high and very high cycle fatigue behaviour of continuous fibre reinforced plastics by conventional and ultrasonic fatigue testing. Compos. Sci. Technol. 2017, 141, 130-136. [CrossRef]

86. Lee, C.S.; Kim, H.J.; Amanov, A.; Choo, J.H.; Kim, Y.K.; Cho, I.S. Investigation on very high cycle fatigue of PA66-GF30 GFRP based on fiber orientation. Compos. Sci. Technol. 2019, 180, 94-100. [CrossRef]

87. Backe, D.; Balle, F. Ultrasonic fatigue and microstructural characterization of carbon fiber fabric reinforced polyphenylene sulfide in the very high cycle fatigue regime. Compos. Sci. Technol. 2016, 126, 115-121. [CrossRef]

88. Cui, W.; Chen, X.; Chen, C.; Cheng, L.; Ding, J.; Zhang, H. Very High Cycle Fatigue (VHCF) Characteristics of Carbon Fiber Reinforced Plastics (CFRP) under Ultrasonic Loading. Materials 2020, 13, 908. [CrossRef] [PubMed]

89. Ding, J.; Cheng, L. Ultra-high three-point bending fatigue performance of nano-silica-reinforced CFRP. Int. J. Fatigue 2021, 145, 106085. [CrossRef]

90. Ding, J.; Cheng, L. Ultra-high three-point bending fatigue fracture characteristics of CFRP modified by MWCNTs and fatigue life data analysis. Compos. Struct. 2021, 259, 113468. [CrossRef]

91. Mayer, H.; Papakyriacou, M. Fatigue behaviour of graphite and interpenetrating graphite-aluminium composite up to 109 load cycles. Carbon 2006, 44, 1801-1807. [CrossRef]

92. Stanzl-Tschegg, S.E.; Papakyriacou, M.; Mayer, H.R.; Schijve, J.; Tschegg, E.K. High Cycle Fatigue Crack Growth Properties of Aramid Reinforced Aluminum Laminates. In Composite Materials: Fatigue and Fracture, Vol. IV; Stinchcomb, W.W., Ashbaugh, N.E., Eds.; ASTM: Warminster, PS, USA, 1993; Volume ASTM STP 1156, pp. 637-652.

93. Papakyriacou, M.; Schijve, J.; Stanzl-Tschegg, S.E. Fatigue Crack Growth Behaviour of Fiber-Metal Laminate Glare 1 and Metal Laminate 7475 with Different Blunt Notches. Fatigue Fract. Eng. Mater. Struct. 1997, 20, 1573-1584. [CrossRef]

94. Fitzka, M.; Catoor, D.; Irrasch, D.; Reiterer, M.; Mayer, H. Fatigue testing of thin CoNiCr wire up to $10^{10}$ cycles. Int. J. Fatigue 2017, 98, 92-100. [CrossRef]

95. Karr, U.; Schuller, R.; Fitzka, M.; Denk, A.; Strauss, A.; Mayer, H. Very high cycle fatigue testing of concrete using ultrasonic cycling. Mater. Test. 2017, 59, 438-444. [CrossRef]

96. Stanzl-Tschegg, S.E. Influence of material properties and testing frequency on VHCF and HCF lives of polycrystalline copper. Int J. Fatigue 2017, 105, 86-96. [CrossRef]

97. Fitzka, M.; Rennhofer, H.; Catoor, D.; Reiterer, M.; Lichtenegger, H.; Checchia, S.; di Michiel, M.; Irrasch, D.; Gruenewald, T.A.; Mayer, H. High Speed In Situ Synchrotron Observation of Cyclic Deformation and Phase Transformation of Superelastic Nitinol at Ultrasonic Frequency. Exp. Mech. 2020, 60, 317-328. [CrossRef] 